\title{
‡USGS
}

science for a changing world

In Cooperation with the Bureau of Reclamation, TSC, Denver, Colorado under the MultiSpecies Conservation Program Work Task G-3 Adaptive Management Research Project and Conservation Measure RASU-6, Lower Colorado Regional Office, Boulder City, Nevada

\section{Techniques for Monitoring Razorback Sucker in the Lower Colorado River, Hoover to Parker Dams, 2006-2007, Final Report}

By Gordon A. Mueller, Richard Wydoski, Eric Best, Steve Hiebert, Jeff Lantow, Mark Santee, Bill Goettlicher, and Joe Millosovich

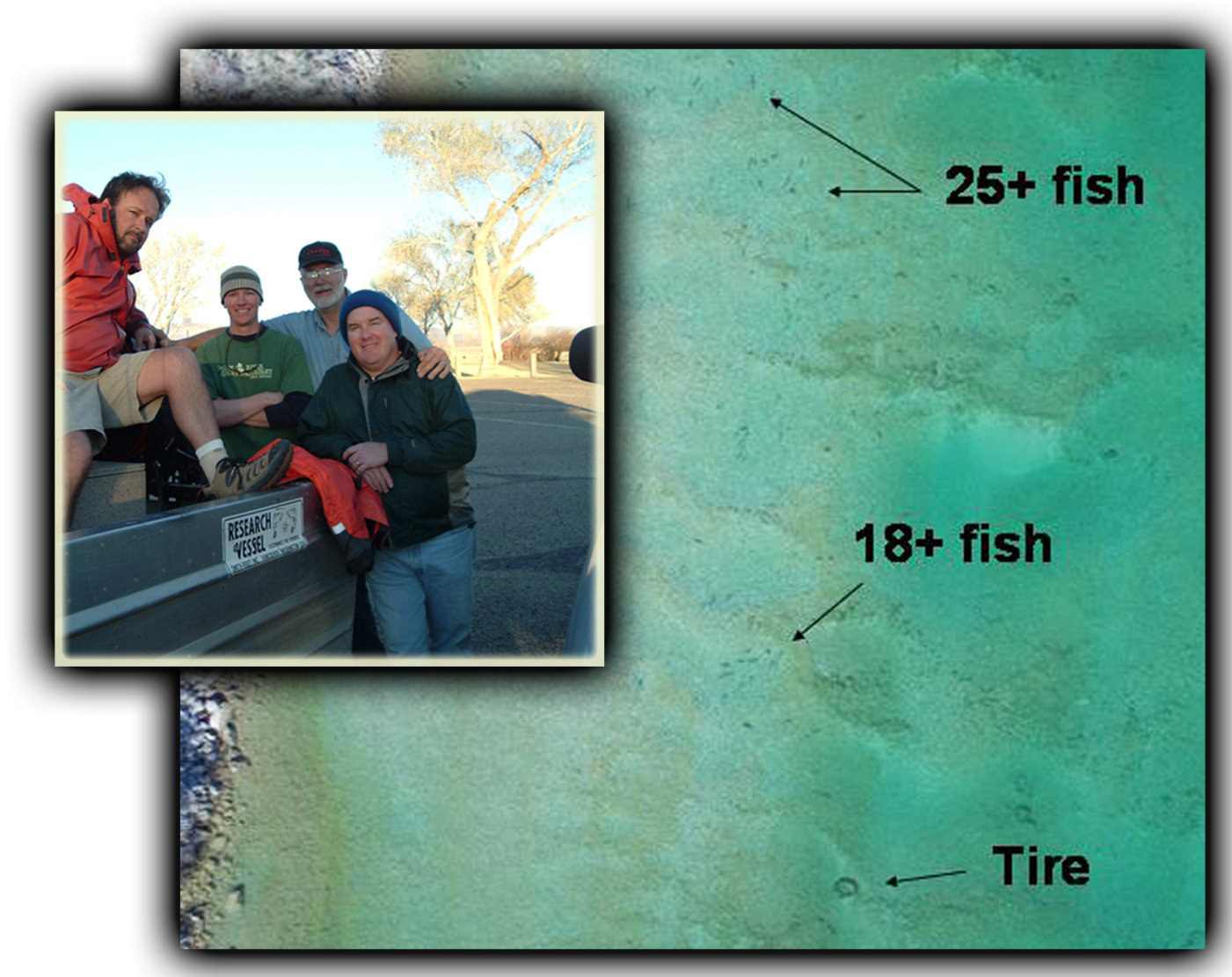

Open-File Report 2008-1245

U.S. Department of the Interior

U.S. Geological Survey 


\section{U.S. Department of the Interior DIRK KEMPTHORNE, Secretary}

\section{U.S. Geological Survey \\ Mark D. Myers, Director}

U.S. Geological Survey, Reston, Virginia: 2008

For product and ordering information:

World Wide Web: http://www.usgs.gov/pubprod

Telephone: 1-888-ASK-USGS

For more information on the USGS - the Federal source for science about the Earth, its natural and living resources, natural hazards, and the environment:

World Wide Web: http://www.usgs.gov

Telephone: 1-888-ASK-USGS

Suggested citation:

Mueller, G.A., Wydoski, R., Best, E., Hiebert, S., Lantow, J., Santee, M., Goettlicher, B., and Millosovich, J., 2008, Development of monitoring techniques for razorback sucker found between Hoover and Parker Dams, 2006-2007, Final Report: U.S. Geological Survey Open-File Report 2008-1245, 34 p.

Any use of trade, product, or firm names is for descriptive purposes only and does not imply endorsement by the U.S. Government.

Although this report is in the public domain, permission must be secured from the individual copyright owners to reproduce any copyrighted material contained within this report. 


\section{Contents}

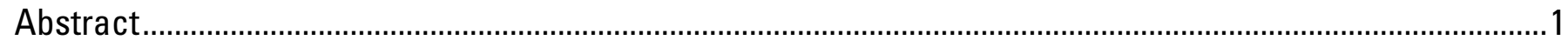

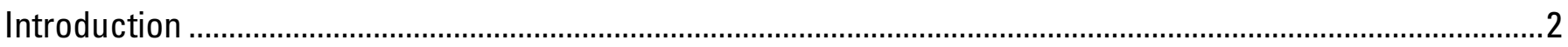

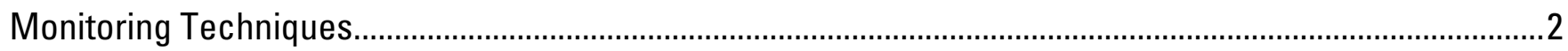

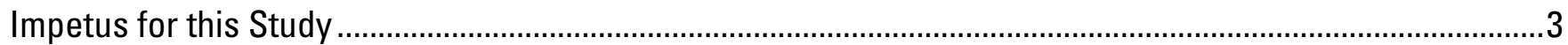

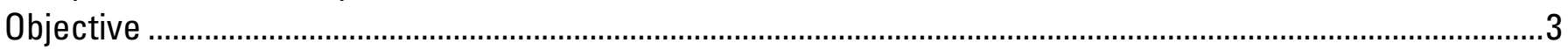

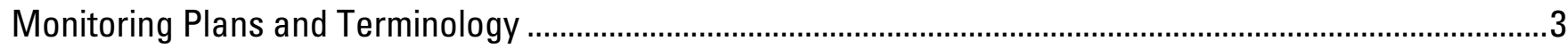

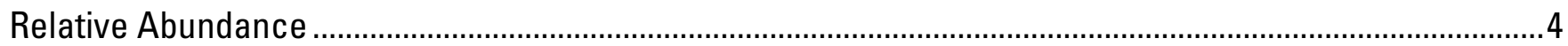

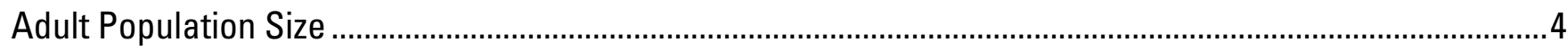

Sample Variance

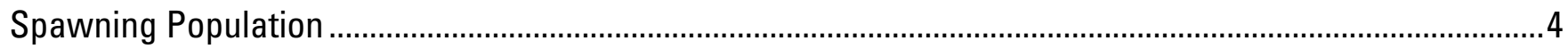

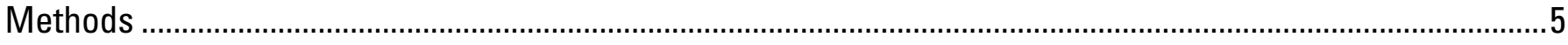

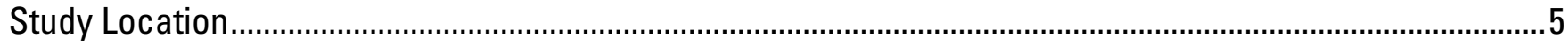

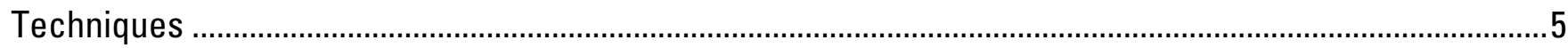

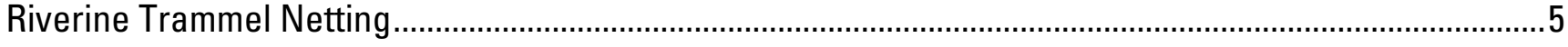

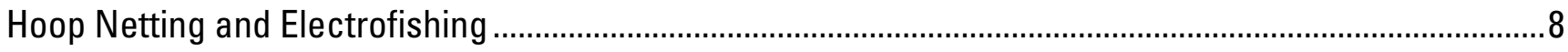

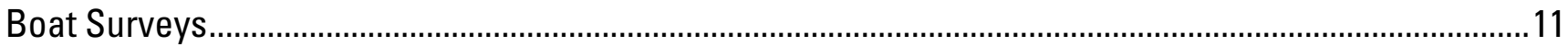

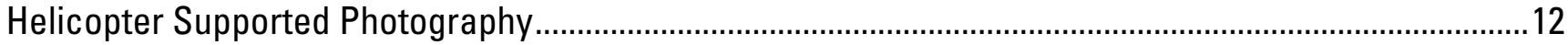

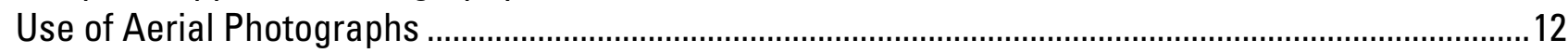

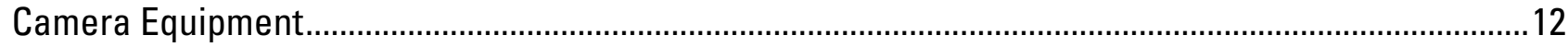

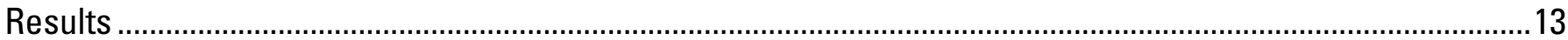

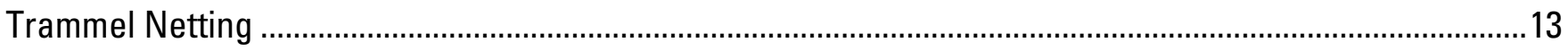

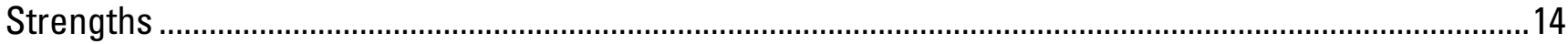

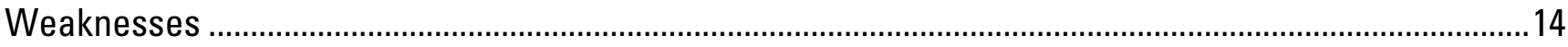

Cost

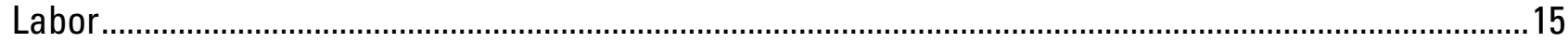

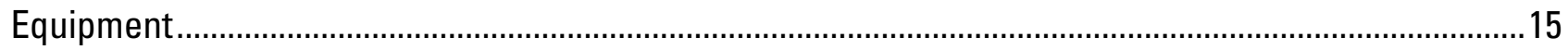

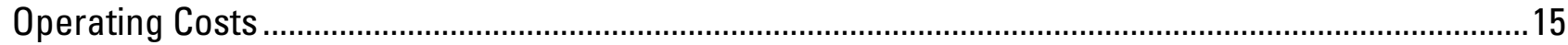

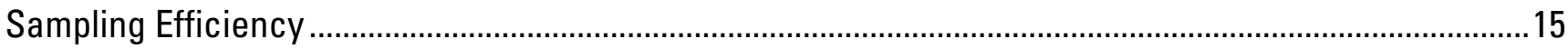

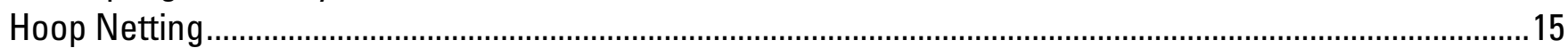

Electrofishing

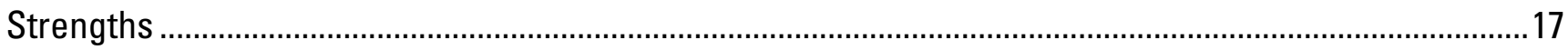

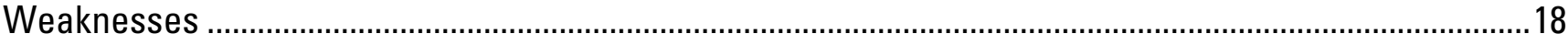

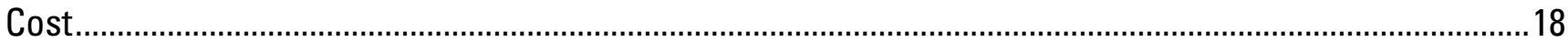

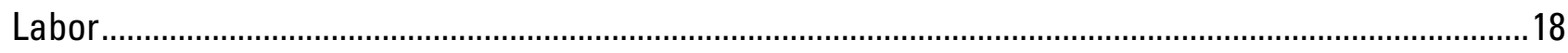

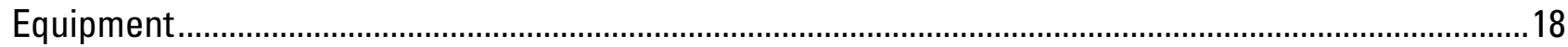

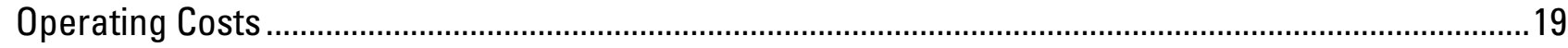

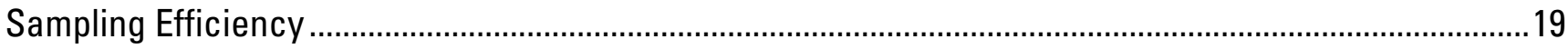

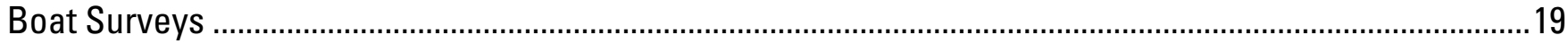

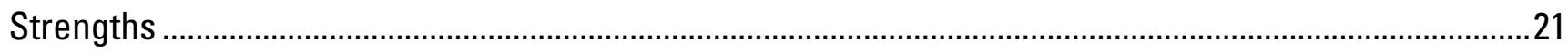

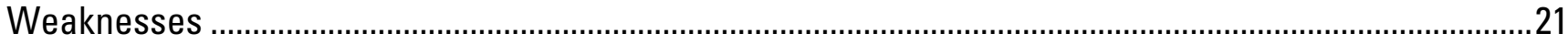

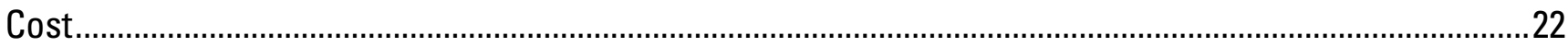

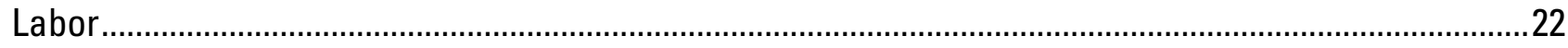

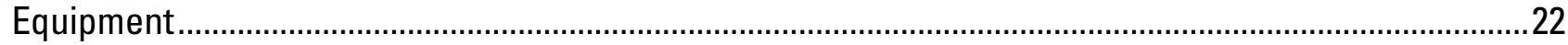




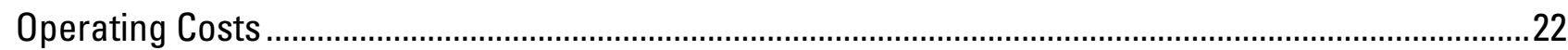

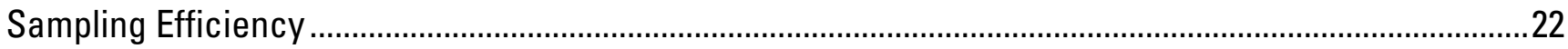

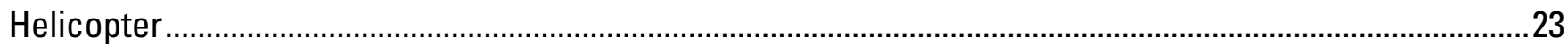

Image Interpretation

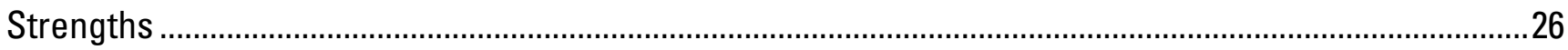

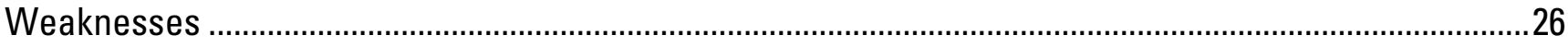

Cost

Labor

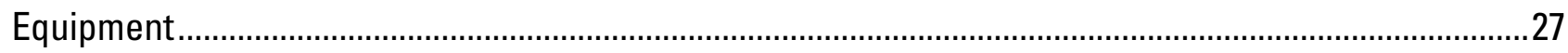

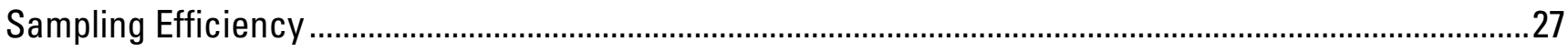

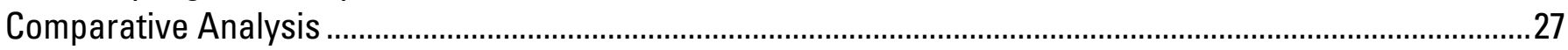

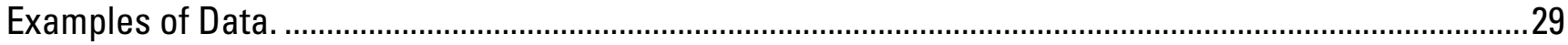

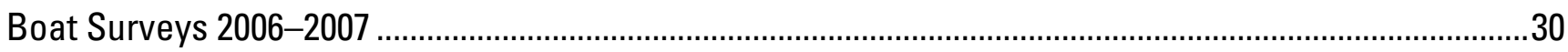

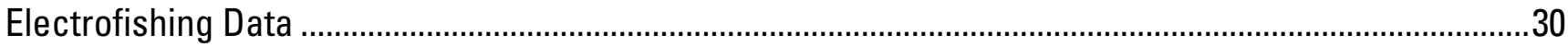

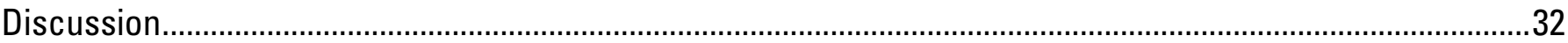

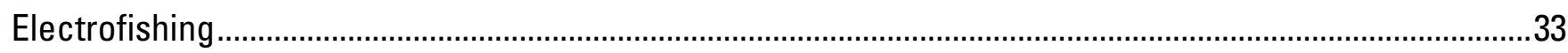

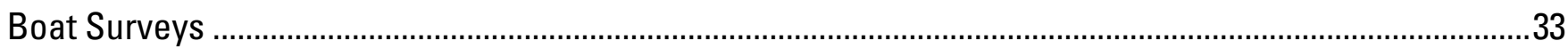

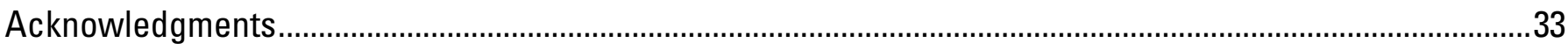

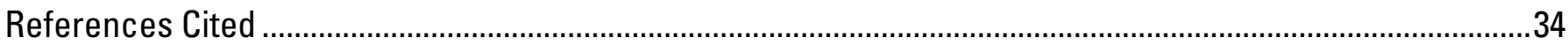

\section{Figures}

1. Central portion of Lake Mohave in the vicinity of Cottonwood Cove Marina, Nevada ...................................6

2. Colorado River reach used by spawning razorback suckers ...........................................................................

3. USBR biologists retrieving a trammel net .......................................................................................

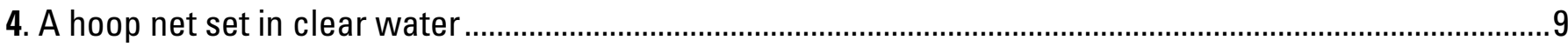

5. California Department of Fish and Game's electrofishing boat is equipped with electrodes that hang from booms extended from the boat's bow. The guard rail and deck provides biologists a platform from which stunned fish can be safely dip-netted from the water.

6. Two additional 500-watt, halogen lights were temporarily attached to the electrofishing boat's guard rail to provide additional illumination for night fish surveys. Fish could be easily observed within $7 \mathrm{~m}$ of the boat, and razorback suckers were readily identifiable.

7. A digital video camera was mounted underneath the helicopter cabin and could be aimed remotely by the pilot.

8. In addition to the video camera, a digital still camera was mounted behind the video camera, and inside the helicopter cabin. The camera was aimed through an open port, and its setting could be adjusted manually during the flight

9. This hoop net was extensively damage when its anchoring system failed and it was dragged downstream by flow. A major portion of the net's bottom was worn-through from rock abrasion.

10. Species composition of fish observed during boat surveys in the Colorado River near Needles, Calif., in 2006. RBS, razorback sucker

11. Aerial image of two groups of fish found in the Needles, California study area in March, 2007. Image enhancement allowed accurate counts but was not sufficient to determine if fish were razorback suckers.

Field verification documented that razorback suckers were located in this area 
12. Enhanced imagery of suspected spawning razorback suckers in Carp Cove, Lake Mohave. Sediment clouds on the left might have been caused by spawning suckers or by feeding carp

13. Surface distortion caused by natural wind or by rotor wash makes it virtually impossible to detect spawning fish. Nearly 3 dozen razorback suckers are in this photograph

14. Distribution of razorback sucker in the Colorado River near Needles, Calif.; distribution based on boat survey data

15. Comparison of the number of razorback suckers (RBS) captured per year, the dollar cost of detecting one fish (capture or identification), and the number of razorback suckers detected per staff day of effort for trammel netting, electrofishing, and boat survey......

\section{Tables}

1. Population estimates derived by surface boat counts of spawning razorbacks counted in the Colorado River near Needles, California, during 2006 and 2007

2. Comparison of fish counts taken by the helicopter crew and from aerial photography of Lake Mohave and the Needles river reach during 16 February and 22 March, 2006. Data represents the total number of fish observed or detected from the imagery

3. Comparison of fish counts taken by the helicopter crew and from aerial photography of Lake Mohave and the Needles river reach during 15 February and 1 March, 2007. Data represents the total number of fish observed or detected from the imagery.

4. Comparison of total cost, cost per razorback sucker, and the number of staff days per razorback sucker caught for trammel netting, electrofishing, and observed by boat surveys, and aerial photography used in the Davis to Parker Dams reach of the Colorado River, Nevada-California, Arizona.

5. Ranking of trammel netting, aerial photography, boat survey and electrofishing in terms of their impact to the resource, cost, and ease of implementation, types of data, and accuracy of resulting data ....................29

6. Comparison of data collected for 2006 and 2007 using visual boat survey techniques ...............................30

7. Comparison of data collected for 2006 and 2007 using electrofishing techniques .........................................32 


\section{Conversion Factors}

Inch/Pound to SI

\begin{tabular}{lcl}
\hline \multicolumn{1}{c}{ Multiply } & \multicolumn{1}{c}{ By } & \multicolumn{1}{c}{ To obtain } \\
\hline millimeter $(\mathrm{mm})$ & 0.03937 & inch (in.) \\
centimeter (cm) & 0.3937 & inch (in.) \\
meter (m) & 3.281 & foot (ft) \\
meter square $\left(\mathrm{m}^{2}\right)$ & 10.76 & square foot $\left(\mathrm{ft}^{2}\right)$ \\
hectare (ha) & 0.01 & kilometer \\
hectare (ha) & 2.47 & acre \\
hectare (ha) & 10,000 & square meters $\left(\mathrm{m}^{2}\right)$ \\
mile (mi) & 1.609 & kilometer $(\mathrm{km})$ \\
nautical mile per hour (knot) & 1.15 & miles per hour $(\mathrm{mph})$ \\
kilogram (kg) & 2.205 & pound $(\mathrm{lb})$ \\
\hline
\end{tabular}

\section{Abbreviations Used in This Report}

\begin{tabular}{ll}
\hline CDFG & California Department of Fish and Game \\
\hline DVD & Digital video disk \\
\hline DNA & diribonucleic acid \\
\hline GPS & Global positioning system \\
\hline ISO & International Organization for Standardization \\
\hline PIT & passive integrated transmitter \\
\hline rpm & revolutions per minute \\
\hline USBR & U.S. Bureau of Reclamation \\
\hline
\end{tabular}




\title{
Techniques for Monitoring Razorback Sucker in the Lower Colorado River, Hoover to Parker Dams, 2006- 2007, Final Report
}

\author{
By Gordon A. Mueller, Richard Wydoski', Eric Best', Steve Hiebert', Jeff Lantow', Mark Santee', Bill \\ Goettlicher', and Joe Millosovich ${ }^{2}$
}

\section{Abstract}

Trammel netting is generally the accepted method of monitoring razorback sucker in reservoirs, but this method is ineffective for monitoring this fish in rivers. Trammel nets set in the current become fouled with debris, and nets set in backwaters capture high numbers of nontarget species. Nontargeted fish composed 97 percent of fish captured in previous studies (1999-2005). In 2005, discovery of a large spawning aggregation of razorback sucker in midchannel near Needles, Calif., prompted the development of more effective methods to monitor this and possibly other riverine fish populations.

This study examined the effectiveness of four methods of monitoring razorback sucker in a riverine environment. Hoop netting, electrofishing, boat surveys, and aerial photography were evaluated in terms of data accuracy, costs, stress on targeted fish, and effect on nontargeted fish as compared with trammel netting.

Trammel netting in the riverine portion of the Colorado River downstream of Davis Dam, Arizona-Nevada yielded an average of 43 razorback suckers a year (1999 to 2005). Capture rates averaged 0.5 razorback suckers per staff day effort, at a cost exceeding $\$ 1,100$ per fish. Population estimates calculated for 2003-2005 were 3,570 (95 percent confidence limits [CL] = 1,306-8,925), 1,768 $(\mathrm{CL}=878-3,867)$ and 1,652 ( $\mathrm{CL}=706-5,164)$; wide confidence ranges reflect the small sample size. By-catch associated with trammel netting included common carp, game fish and, occasionally, shorebirds, waterfowl, and muskrats.

Hoop nets were prone to downstream drift owing to design and anchoring problems aggravated by hydropower ramping. Tests were dropped after the 2006 field season and replaced with electrofishing.

Electrofishing at night during low flow and when spawning razorback suckers moved to the shoreline proved extremely effective. In 2006 and 2007, 263 and 299 (respectively) razorback suckers were taken. Capture rates averaged 8.3 razorback suckers per staff day at a cost of $\$ 62$ per fish. The adult population was estimated at 1,196 $(925-1,546)$ fish. Compared with trammel netting, confidence limits narrowed substantially, from \pm 500 percent to \pm 30 percent, reflecting more precise estimates. Bycatch was limited to two common carp. No recreational game fish, waterfowl, or mammals were captured or handled during use of electrofishing.

Aerial photography (2006 and 2007) suggested an annual average of 580 fish detected on imagery. Identification of species was not possible; carp commonly have been mistaken for razorback

\footnotetext{
${ }^{1}$ U.S. Bureau of Reclamation

${ }^{2}$ California Department of Fish and Game
} 
sucker. Field verification determined that the proportion of razorback suckers to other fish was $3: 1$. On that basis, we estimated 435 razorback suckers were photographed, which equals 8.4 razorback suckers per staff day at a cost of $\$ 78$ per fish. The data did not lend itself to population estimates.

Fish were more easily identified from boats, where their lateral rather than their dorsal aspect is visible. On average, 888 razorback suckers were positively identified each year. Observation rates averaged 29.6 razorback suckers per staff day at a cost less than $\$ 18$ per fish observed. Sucker densities averaged 20.5 and 9.6 fish/hectare which equated to an average spawning population at Needles, Calif., of 2,520 in 2006 and 1152 in 2007. The lower 2007 estimate reflected a refinement in sampling approach which removed a sampling bias.

Electrofishing and boat surveys were more cost effective than other methods tested, and they provided more accurate information without the by-catch associated with trammel netting. However, they provided different types of data. Handling fish may be necessary for research purposes but unnecessary for general trend analysis. Electrofishing was extremely effective but can harm fish if not used with caution. Unnecessary electrofishing increases the likelihood of spinal damage and possible damage to eggs and potential young, and it may alter spawning behavior or duration. Boat surveys, on the other hand, only minimally affect spawning fish. A possible combination of these techniquesalternating between years as determined by information needs - is a practical option. This report provides suggestions to further refine electrofishing and boat surveys to minimize potential trauma to fish while improving the efficiency and effectiveness of monitoring results.

\section{Introduction}

\section{Monitoring Techniques}

Techniques to monitor razorback sucker (Xyrauchen texanus) were developed in the late 1970s at Lake Mohave (Minckley, 1983; Marsh and others, 2005). Trammel netting (4- to 12-cm mesh), supplemented by electrofishing was effective at capturing spawning suckers that congregated along the shallow shoreline. Razorback sucker spawn in late winter (January through April) when game fish are less active, thereby reducing by-catch of untargeted species. Regardless, some loss of by-catch does occur. During the past two decades, trammel netting has remained the primary method used to monitor razorback sucker populations in lower Colorado River basin reservoirs (that is, Lakes Mead and Mohave). Fish are netted, marked, and released, and then the population is sampled again at a later date. Estimates are based on the ratio of marked to unmarked fish (Marsh and others, 2005).

Trammel nets are effective in backwaters, where fish concentrate during the winter because the water is slightly warmer and more food is available. Unfortunately, netting in backwaters leads to bycatch of nontargeted species - common carp, game fish and, occasionally, shore birds, waterfowl, and muskrats. Fish may be returned unharmed, but birds and mammals typically are lost. Nets and equipment have also been vandalized, stolen, or ruined by muskrats or beaver. Locations where fish are commonly found are also popular recreation areas. Nets or netting activity regularly attracts curious spectators and occasionally triggers phone inquires to law-enforcement agencies.

The Lake Havasu Fisheries Improvement Program stocked 30,000 relatively large (greater than 30-cm-long) razorback suckers into Lake Havasu from 1994 through 2002; monitoring was conducted to determine the success of these introductions (Mueller, 2003; Wydoski and Mueller, 2006). Trammel nets were used to capture razorback suckers from 1999 to 2005 in the river reach between Davis Dam and Lake Havasu. Rivers were more difficult to sample than reservoirs. Nets tended to collapse in the current, especially if they contained any debris. Despite substantial work, researchers on average captured fewer than 50 razorback sucker a year, and spawning aggregations evaded discovery until 2005. 


\section{Impetus for this Study}

In 2005, a large spawning congregation of razorback suckers was discovered by following fish carrying radio transmitters. Several hundred spawning suckers were observed congregated upstream of Needles, Calif. (Wydoski and Mueller, 2006). Subsequent sampling and collection of razorback sucker larvae downstream confirmed active spawning. These larvae were the first documentation of razorback sucker spawning downstream of Lake Mohave since the early 1950s (Douglas, 1952). It probably represents the largest riverine spawning congregation in existence.

The discovery was exciting. However, river conditions presented perplexing challenges for sampling. Razorback suckers chose to spawn mid-channel in fairly strong $(>0.5 \mathrm{~m} / \mathrm{s})$ currents compared with the tranquil shoreline of Lake Mohave or historically for Lake Havasu (Douglas, 1952). Spawning razorback suckers were found throughout a $12-\mathrm{km}$ reach and were concentrated near residential and vacation homes. Mid-channel netting was impractical owing to strong currents. Slack-water netting (to catch spawning razorback suckers adjacent jetties and private docks) was impractical owing to safety and public-conflict issues. Other sampling methods needed to be developed and tested. This study stemmed from that need.

\section{Objective}

The objective of this study was to identify and test new techniques for monitoring razorback sucker that could increase the accuracy of population estimates and reduce by-catch of nontargeted species, costs, and conflicts with the public. Initially, these techniques were both direct (actual capture), and indirect (remote sensing), some successfully used for other species. For instance, aerial and surface reconnaissance techniques have been used for decades to monitor salmon spawning in the Pacific Northwest and other parts of the world. Boats, fixed-wing aircraft, and helicopters are used to monitor the distribution and abundance of salmon redds, and to count spawning individuals and post-spawning carcasses (West and Goode, 1987; Catalano and others, 1997; Killam and Harvey-Arrison, 2003). Elsewhere these approaches have proven cost effective and have produced minimal effect on the resource. They have been widely adopted by wildlife managers and agencies (Skinner and others, 1997; Quang and Lanctot, 1991).

Bureau of Reclamation (USBR) uses its helicopter to take high resolution videography of the lower Colorado River's infrastructure during inspection flights. The helicopter is also used to locate spawning razorback sucker for the purpose of collecting larvae on Lake Mohave. These services are provided to other agencies for the area between Davis and Parker Dams. We are unaware of any prior attempt to examine its potential use to photograph or quantify abundance of spawning razorback suckers. In addition, boat surveys were previously used to determine the distribution and abundance of flannelmouth sucker (Catostomus latipinnis) in the Laughlin area (Mueller, 2003). We felt that this approach might also work for razorback suckers in this section of river.

The direct method we evaluated used specially constructed hoop nets that include an internal chamber which can contain a female. Males are attracted to sexually active females, who we suspect release reproductive pheromones. We tested whether live females would lure males into fish traps. Our goal was to coordinate efforts with an ongoing study of flannelmouth suckers (Best and Lantow, 2007) in the application, testing, and refinement of methods that might be applied in the lower Colorado River between Parker and Davis Dams and for Lake Mohave annual monitoring efforts.

\section{Monitoring Plans and Terminology}

This study was designed to test, refine, and present information pertaining to razorback-suckermonitoring options. It was not intended to develop a specific monitoring program or to develop specific 
information regarding this fish population. Not all monitoring techniques produce the same type or the same quality of information. For example, visual surveys may be adequate to monitor relative abundance trends but are inadequate to determine more specific research questions pertaining to movement, individual growth, or sexual condition. Resource agencies and researchers need to determine information needs and then design an appropriate monitoring program. The information presented here should help in those decisions.

Examples of the data that can be expected from these techniques are discussed in later sections of this report. Because understanding the terminology used is critical, specific terms used to describe data sets are explained here.

\section{Relative Abundance}

Relative abundance refers to the collection of annual or seasonal trend information that is used to determine if populations are declining, stable, or increasing. Netting and electrofishing data are typically presented in terms of catch per unit effort that represent numbers of fish captured per net (for example, 7 fish captured per over night net set), per surface area of net used (for example, 7 fish captured per 100 $\mathrm{m}^{2}$ net set), or per time (for example, 7 fish captured per 15 minutes actual shocking time, or 7 fish observed per 15 minutes). This information by itself is not a measurement of population size. An example of a trend set is as follows: "We captured 23, 32, and 45 fish per 15 minutes of actual shocking time from 2005 through 2007." That statement suggests that the population is growing because of the numbers increase with time.

\section{Adult Population Size}

Adult population size refers to the actual number of sexually active individuals, regardless of location. Estimates of adult population size incorporate several necessary assumptions. First, because the fish mortality rate is unknown, to minimize this factor we use only fish marked from the previous year to develop those estimates and assumed $100 \%$ survival. Second, we assume that adults freely range between Davis and Parker Dams. Current (2008) telemetry studies are examining these issues, and it appears that this assumption is mostly valid (Rich Wydoski, USBR, 2008, oral communication). Third, it assumes that the Needles spawning reach is the primary spawning area in the Colorado River between Parker and Davis Dams, but that if there are others, then individual fish prefer no one site. (These assumptions may be true, partially true, or incorrect).

\section{Sample Variance}

Sample variance provides information used to estimate confidence limits. For example, the adult population estimate for 2007 was 1,200 with a 95 percent confidence interval of 800 to 1,600 fish. Thus, in repeated random sampling, we would expect 95 percent of similarly obtained population estimates and confidence intervals to fall within the range of 800 to 1,600 fish.

\section{Spawning Population}

The spawning population refers to the number of adult fish found in a specific spawning reach; it is a portion of the entire adult population. Spawning population more accurately measures spawning activity or use of a specific location. We assume that most adults spawn each year and in the same locations; however, total spawning can occupy several weeks. For example, boat surveys conducted on three separate trips within a 5-week period in 2007 in the Needles spawning reach estimated an average spawning population of 1,152 fish during that time. This number represents only suckers found in the Needles spawning reach, not those found elsewhere. Estimates based on these surveys are conservative 
because spawning occupies about 3 months and may not include fish that had spawned before these counts and left and those that had not yet spawned, but will. It is also possible that spawning activity may fluctuate with time and that in some years fish may spawn in a different location.

\section{Methods}

\section{Study Location}

This study investigated two known razorback sucker spawning areas, one on a reservoir reach on Lake Mohave, and the second (Needles spawning reach) a 50-km portion of the Colorado River that extends immediately downstream of Davis Dam. Biologists have monitored razorback sucker spawning in Lake Mohave for more than 3 decades (Minckley and others, 1991). In general, razorback suckers spawn mid-reservoir along the shallow shoreline (fig. 1). We were guided to spawning congregations on Lake Mohave based on information provided by USBR biologists working that area. Primary sites are Yuma Cove, Tequila Cove, and Carp Cove.

The river portion of the study area involved a 12-km reach of the Colorado River just north (upstream) of Needles, Calif. Initial surveys at the end of January in 2006 and 2007 located spawning congregations between the Needles Bridge (Highway 95, River Mile 245) and Willow Valley Estates (River Mile 253). Spawning groups were found primarily in laminar flow over clean, cobble-gravel substrate and generally at depths of 1-3 m. These areas had an estimated velocity of approximately a half meter per second $(\mathrm{m} / \mathrm{s})$. Other individuals and small groups were observed in deeper holes and swifter waters. We suspect these fish were staging, convalescing (females between spawning events), or migrating between spawning groups. We sampled between Jack Smith Park and Willow Valley Estates where the greatest number of razorback suckers were observed (fig. 2). This study focused on testing monitoring techniques in this river reach where spawning razorback suckers were concentrated.

\section{Techniques}

In 2006, this study tested and compared the effectiveness of three monitoring alternatives to trammel netting in a riverine environment. The experimental methods were hoop nets containing female suckers, visual counts of fish in boat surveys, and aerial photography. In 2007, hoop netting was dropped and electrofishing was added as a monitoring technique (rather than simply as a method to obtain females for hoop nets). Results from the 2006 and 2007 tests were compared with results from seven years (1999-2005) of trammel netting in both a reservoir and river reach to determine cost effectiveness, types, and quality of data and other resource and social issues. A description of those approaches follows.

\section{Riverine Trammel Netting}

Trammel netting was conducted from 1999 to 2005 in previous studies described in Mueller, 2003; Wydoski and Mueller, 2006. Nets were set periodically from early January through early April; field seasons generally averaged 6 field trips of 5 days each. Unlike gill nets, which normally capture fish by entanglement around the gills, trammel nets are constructed of three net panels which "bag" the fish, rather than constricting their gills. Trammel nets were typically $50 \mathrm{~m}$ long and $2 \mathrm{~m}$ tall and were constructed of 30-cm mesh (outer panel), and 5-cm mesh (inner panel). Samples were taken Monday through Thursday; an average of 12 to 16 nets were set in late afternoon and retrieved shortly after dawn 


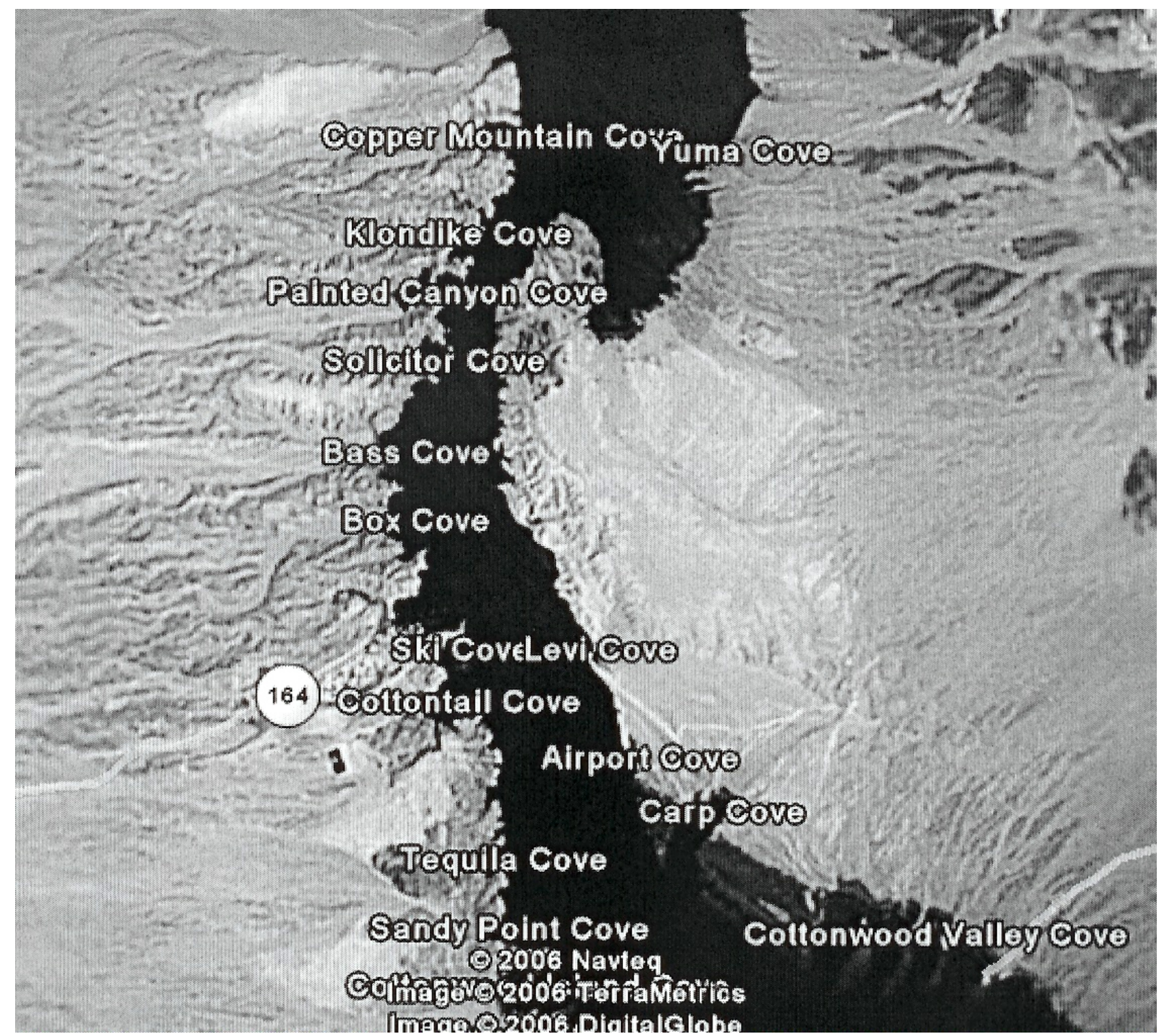

Figure 1. Central portion of Lake Mohave in the vicinity of Cottonwood Cove Marina, Nevada. 


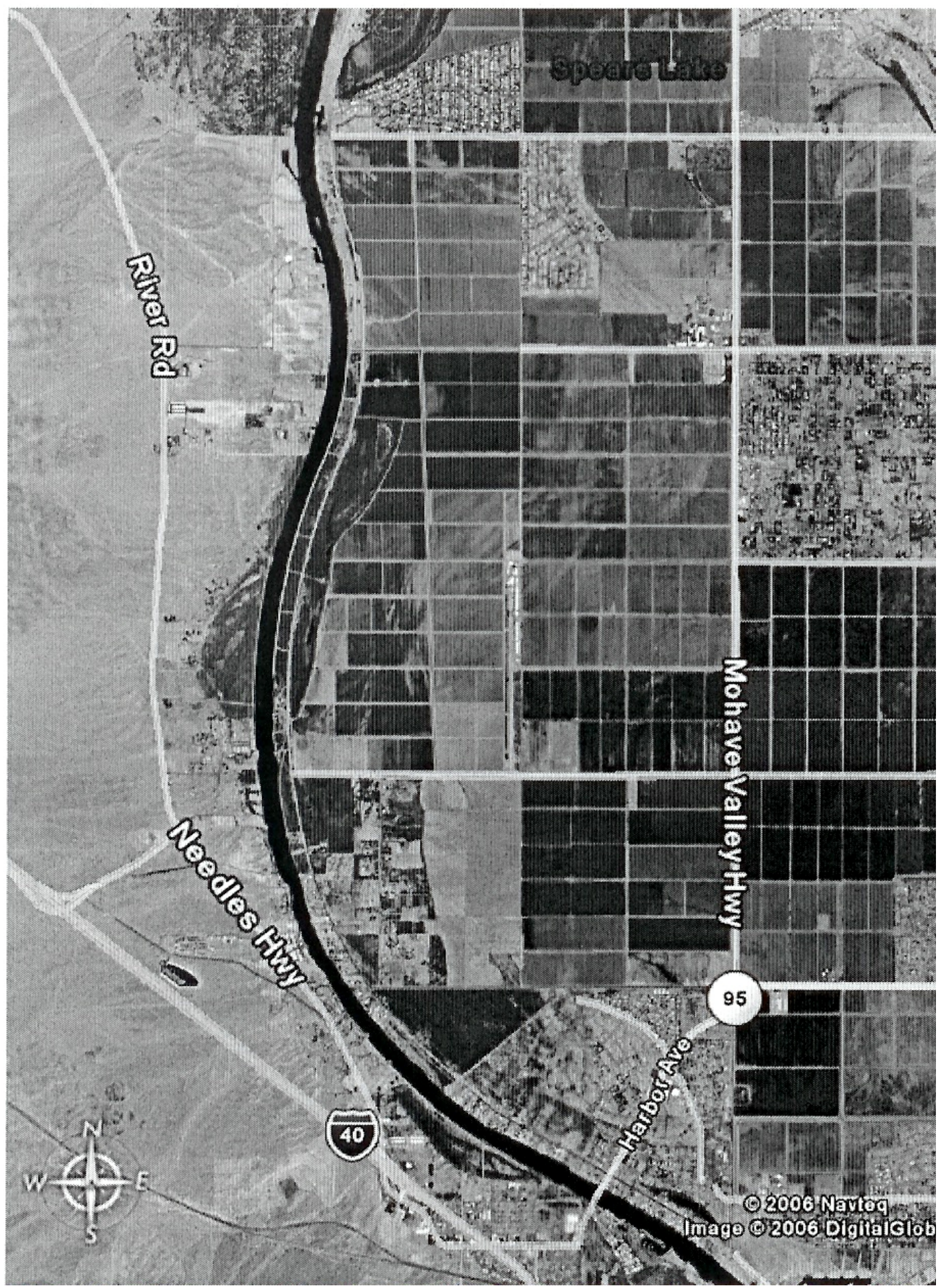

Figure 2. Colorado River reach used by spawning razorback suckers. The reach includes a $12 \mathrm{~km}$ section of the Colorado River located upstream of Highway 95 bridge, which is located just north (upstream) of Needles, Calif. 
the following day. The number of nets set varied dependent upon the crew size, which ranged from 2 to 5 people. Nets were set in slack-water habitats such as backwaters and downstream of jetties (fig. 3). The first couple of years, nets were set every $3 \mathrm{~km}$ along the $100-\mathrm{km}$ river reach and in the major backwaters in upper Lake Havasu. Netting was later focused on those areas where suckers were commonly captured. All native fish were injected with a passive integrated transmitter (PIT) tag so they could be identified later. They were weighed (in grams), measured (in millimeters), and released.

\section{Hoop Netting and Electrofishing}

Trammel netting in Lake Mohave generally produces three times as many razorback sucker males as females. Males are typically concentrated along shore over spawning bars where they are susceptible to trammel netting. Ripe females visit but do not reside in these areas between spawning events, limiting their exposure to capture. In contrast, previous attempts to capture flannelmouth suckers

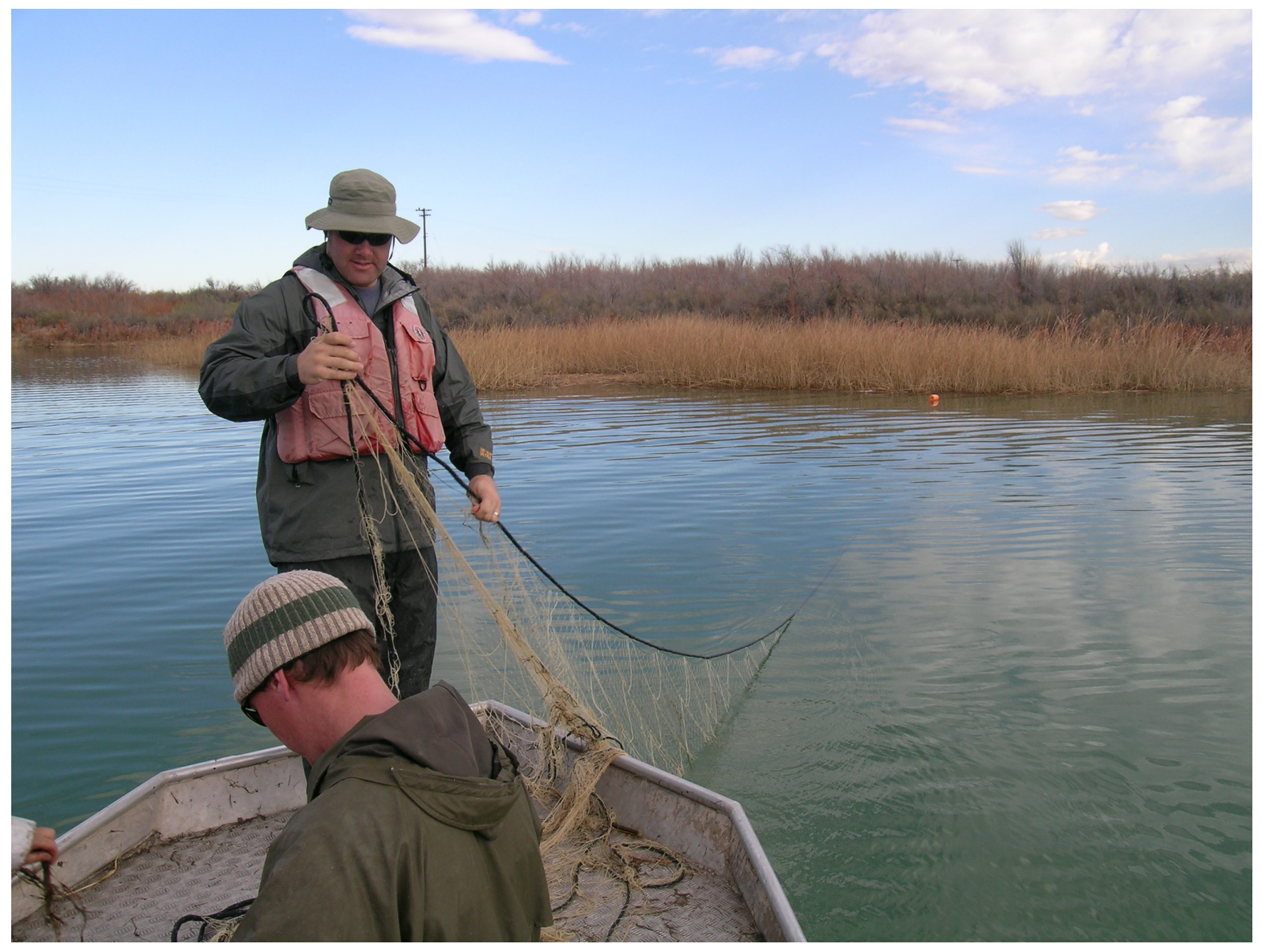

Figure 3. USBR biologists retrieving a trammel net. Trammel nets are generally tied perpendicular to shore and set toward deeper water. 
(Mueller, 2003) in the river downstream of Davis Dam collected three times as many females as males. This sexual bias resulted because females are more susceptible to capture than males. Flannelmouth sucker females convalesce between spawning events along shore and in backwaters where they are relatively easy to capture. Flannelmouth males, on the other hand, concentrate mid-channel at depths (>2 m) and velocities that made electrofishing and trammel netting ineffective. In 2005 at their discovery site, we observed razorback sucker males inhabiting similar mid-channel habitat and anticipated similar problems accessing them.

We theorized that hoop nets might prove more effective under this type of field condition. Four hoop nets were constructed with trailing leads and a chamber at the net's cod end (in addition to the trap) to hold females (fig. 4). The traps were constructed of 2.4-cm mesh netting, had three 1-m hoops, were double-throated, were $5 \mathrm{~m}$ long, and had a rectangular frame at the entrance for stabilization. The holding chamber was constructed of $1-\mathrm{cm}$ netting to provide the females a velocity refuge and equipped with a zipper for easy access. The theory was to attract and capture sexually active males using suspected pheromones released by sexually ripe females placed in the traps. It was planned to set half the sets with females and the other half without fish.

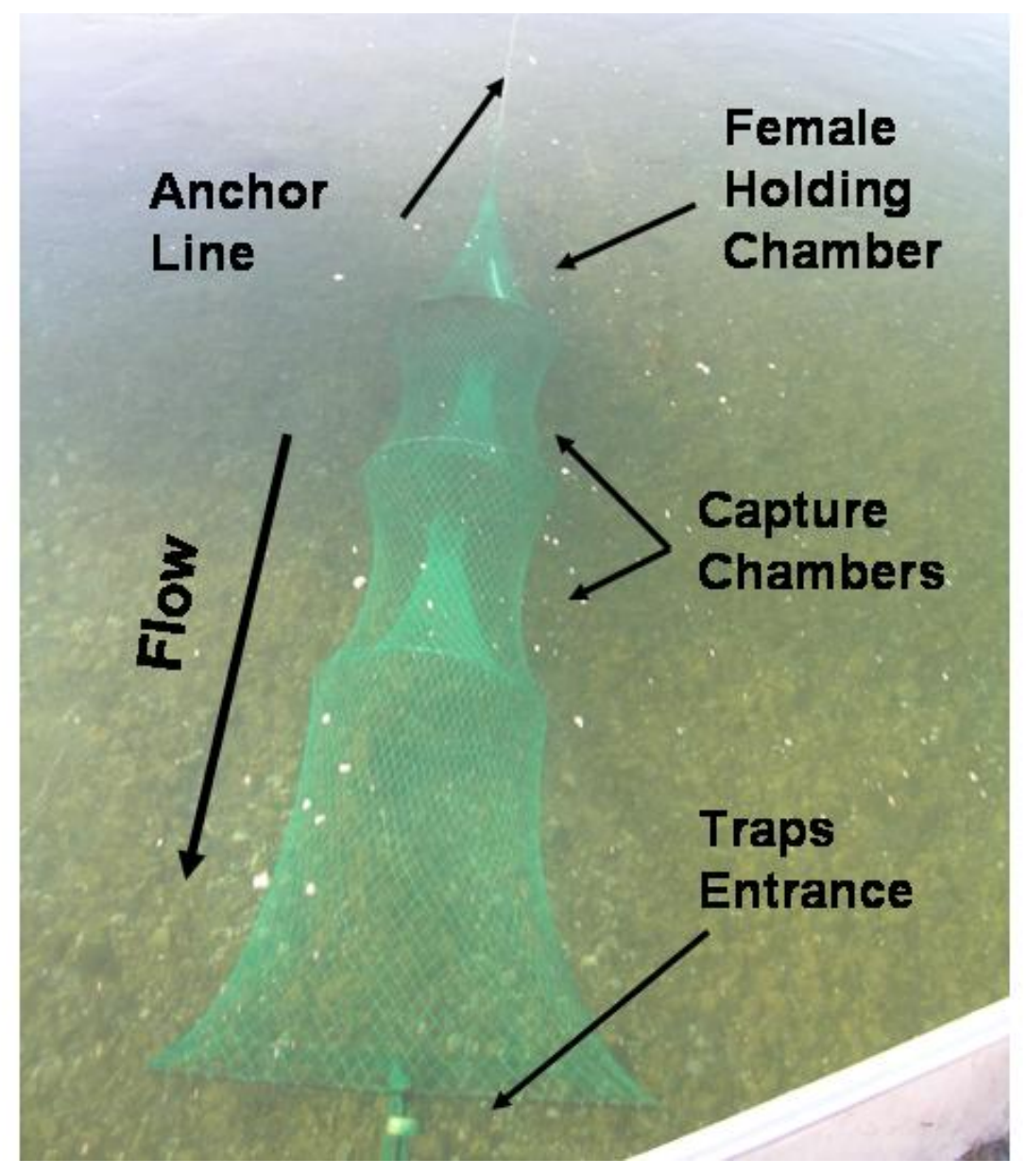

Figure 4. A hoop net set in clear water. 
Traps were set adjacent to a fish spawning site. Large claw anchors $(20 \mathrm{~kg})$ were attached to the cod end of the nets using $10 \mathrm{~m}$ of rope. The anchors were set and then the trap was deployed as the boat drifted downstream. During the drift, one or two female suckers were carefully placed inside the compartment, and the net was lowered into the river. The trap's entrance faced downstream and was equipped with a 10-m net lead. A 15-m rope and float was attached to the end of the lead.

Females used to entice males into the traps were captured by electrofishing. Two electrofishing boats were available for use, one from USBR and the other from California Department of Fish and Game (CDFG). One was equipped with a Smith-Root GPP 5.0 electrofisher, and the other with a SmithRoot 7.5 electrofisher (fig. 5). Both crews routinely sampled the study area and other portions of the river and were well equipped and trained. Fish respond to direct current with an involuntary swim attraction and are stunned. They are immediately removed from the water using dip-nets and placed in a large holding tank to recover. When done properly, the fish fully recover within a few minutes. We collected four females, which were transported and placed inside the enclosures of two hoop nets.

Nets were visually checked daily and allowed to fish for two days. All fish captured during electrofishing, including the females, were checked for tags (PIT and wire), measured, weighed, and then released unharmed.

Razorback suckers proved more susceptible to electrofishing than did flannelmouth sucker in previous attempts at collecting (Mueller, 2003). Problems associated with hoop netting caused us to divert time and resources from assessing hoop nets to electrofishing. Hoop netting proved ineffective, and electrofishing worked better than anticipated.

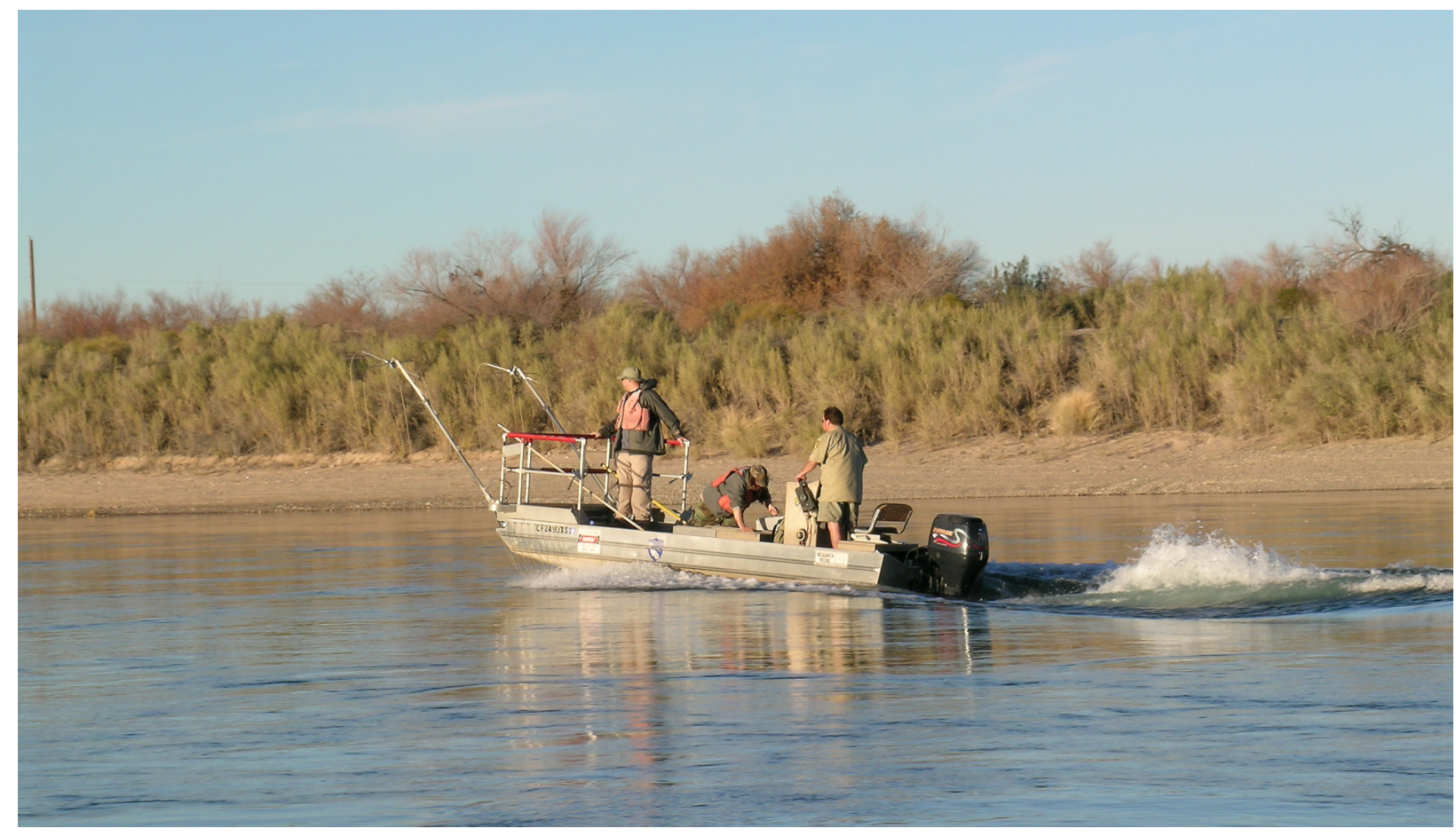

Figure 5. California Department of Fish and Game's electrofishing boat is equipped with electrodes that hang from booms extended from the boat's bow. The guard rail and deck provides biologists a platform from which stunned fish can be safely dip-netted from the water. 


\section{Boat Surveys}

Boat surveys developed in a previous study (Mueller, 2003) were adapted for this study. Water visibility was generally good, often ranging 3-5 m. Fish were commonly observed from shoreline and from boats. Earlier attempts to electro-shock flannelmouth suckers proved ineffective because fish were too deep to stun or net; however, they could easily be seen. While they could not be collected, we could identify and count them regardless of the species as we floated by. Razorback sucker density and population estimates were developed using the same approach.

Boat surveys of the river portion were conducted by a minimum crew of two: a spotter to identify and count fish (razorback sucker and other species), and a driver to pilot and record data (fig. 6). A standard protocol was developed to measure number of fish per unit effort, in units of time (fish per 15 minutes) and surface area (fish per $\mathrm{m}^{2}$ ). A spotter positioned on the boat's bow judged the lateral distance at which fish could effectively be identified and passed this information along to be recorded. That distance usually ranged from 3 to $10 \mathrm{~m}$ depending upon conditions (wind, turbidity, lighting, and glare). Both night and day surveys were performed. The pilot operated the boat at $2-5 \mathrm{~km}$ per hour and recorded data in 15-min increments. Global positioning system (GPS) coordinates were marked at the beginning and end of each survey, providing an accurate distance. This protocol was modified in the second trip to measure accumulated distance in a "route" mode. These measurements were used to calculate the surface area where fish were observed (fish per $\mathrm{m}^{2}$ ) or the number of fish observed per unit time (fish per $15 \mathrm{~min}$ ), similar to standard protocols developed for electrofishing. Only fish positively identified were counted. Surveys were conducted while motoring both upstream $(2,000$ motor revolutions per minute (rpm)) and downstream $(1,000 \mathrm{rpm})$.

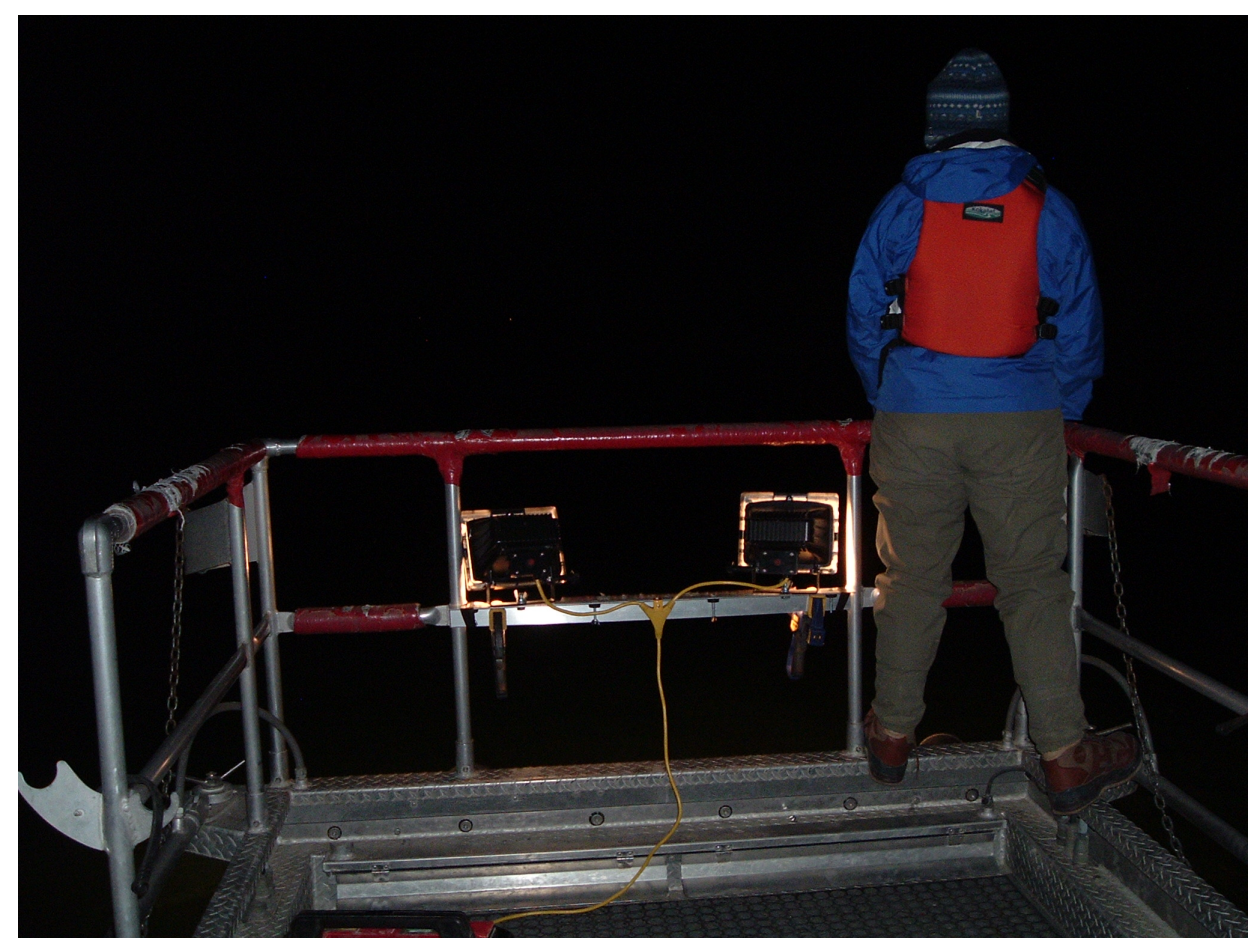

Figure 6. Two additional 500-watt, halogen lights were temporarily attached to the electrofishing boat's guard rail to provide additional illumination for night fish surveys. Fish could be easily observed within 7 $\mathrm{m}$ of the boat, and razorback suckers were readily identifiable. 


\section{Helicopter Supported Photography}

\section{Use of Aerial Photographs}

Aerial photographs were taken with high-resolution digital cameras over known razorback sucker spawning areas. Because a helicopter is already used to locate spawning razorback suckers on Lake Mohave, we tested the equipment over consistent spawning grounds in the lake (Yuma, Tequila, and Carp Coves) (fig. 1). Once the helicopter crew felt confident they were getting imagery, they were to film known spawning areas in the reservoir and then move downstream to photograph suckers spawning in the Colorado River near Needles, Calif. (fig. 2). Locations of riverine spawning were determined by a boat reconnaissance 2 weeks before the flight. In 2006, surveys were conducted on February 16 and March 22. Techniques were refined based on results and a standard protocol was developed and tested in 2007, on February 15 and March 1.

\section{Camera Equipment}

The helicopter was equipped with a nose-mounted video camera which the pilot used to determine the approximate view that was being photographed (fig. 7). The video camera was a Sony HVR-Z1U. Camera settings were the same for both trips, and included: shutter speed was 1/500 second, aperture was set on 'auto', ND filter was set on 'off'; gain set on $18 \mathrm{db}(\mathrm{H})$; and the lens was set at about $40 \%$ full wide angle for the first trip and set full wide angle with various levels of zoom used when fish were encountered during the second trip.

Higher resolution imagery was collected with a Nikon D2X still camera equipped with a $28 \mathrm{~mm}$ lens. The camera was aimed through a port in the bottom of the cabin (fig. 8). The camera had an image resolution of 12.7 megapixels (an image of 4,288 by 2,848 pixels). The digital camera operated from a time delay, taking still pictures every $4 \mathrm{~s}$, and downloading to a hard drive on a laptop computer. This method allowed us to enlarge ("zoom in" on) images of suspected fish during analysis, something that

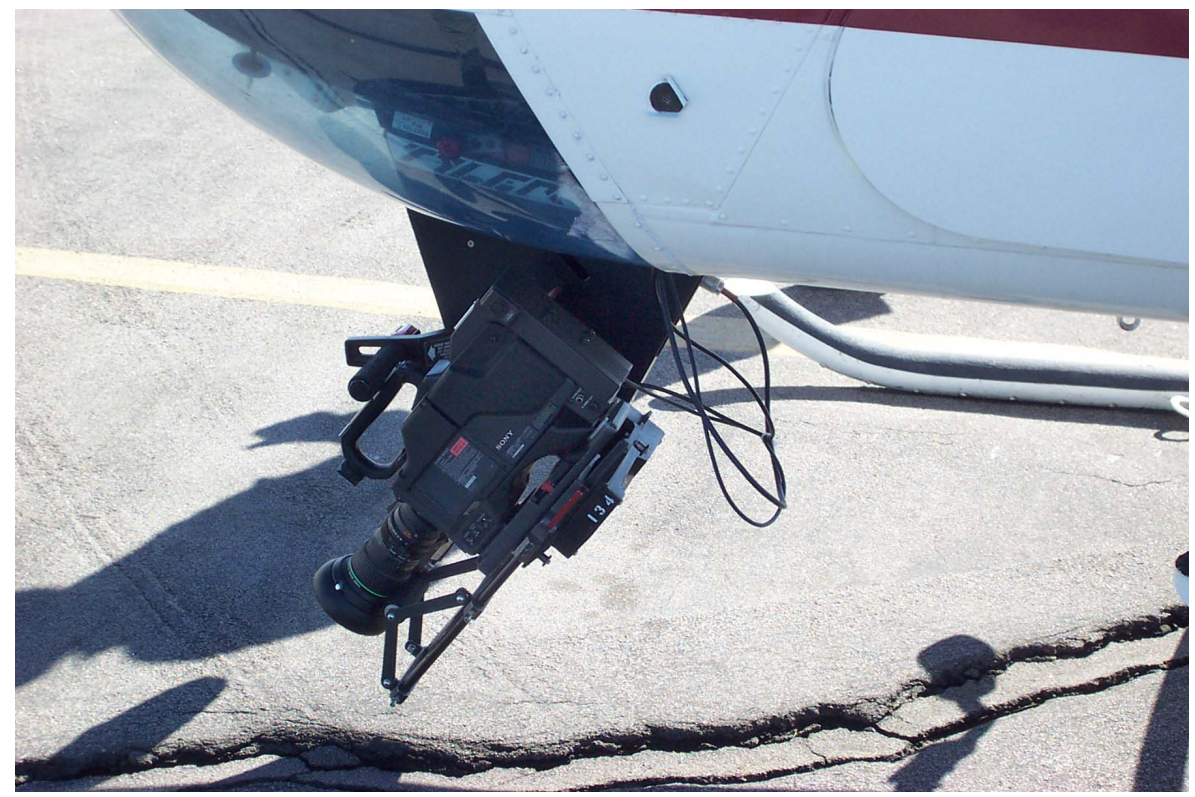

Figure 7. A digital video camera was mounted underneath the helicopter cabin and could be aimed remotely by the pilot. 


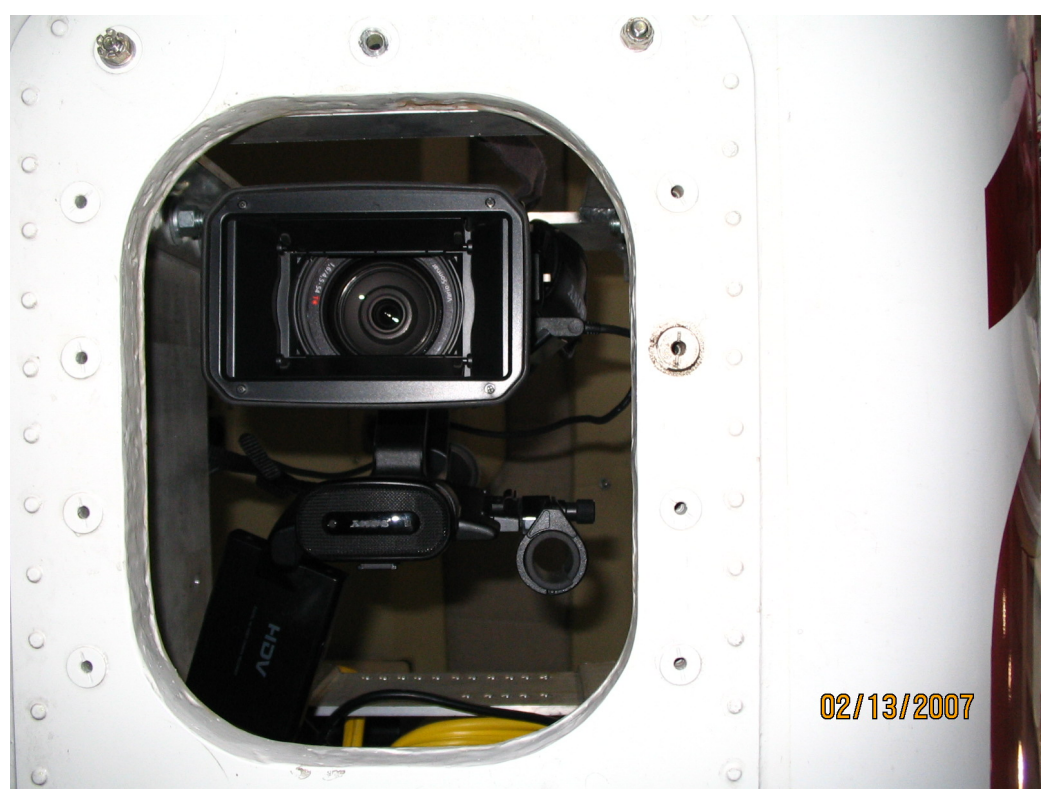

Figure 8. In addition to the video camera, a digital still camera was mounted behind the video camera, and inside the helicopter cabin. The camera was aimed through an open port, and its setting could be adjusted manually during the flight.

we could not do with videography. During the February 16, 2006, trip, the camera settings were set at a shutter speed that ranged between $1 / 80$ to $1 / 125 \mathrm{~s}$, an ISO of 250 , and aperture priority of 7.1. On the March 22, 2006, trip, the shutter speed was set at 1/250, an ISO of 400, and an aperture set on "auto," while the lens focus was set on infinity. These settings were also used in 2007.

The cameras were operated from inside the helicopter cabin by two technicians and were linked to laptop computers where imagery was downloaded, referenced to GPS location, and stored on hard disk. The electronic files were downloaded to digital video disks (DVDs) and viewed using the DVD recorder software, Moonlight. This program allowed images to be tracked by GPS location and time, and images could be magnified later.

Flight protocols were refined in the field by filming spawning suckers in Lake Mohave before proceeding to the river portion of the study area. In 2006, the helicopter flew at an elevation of approximately $150 \mathrm{~m}$ and an air speed of approximately $40 \mathrm{knots}(46 \mathrm{mph})$. The flight pattern followed close to shore, and along the river corridor which provided imagery that covered approximately 30 percent of the channel's width $(150 \mathrm{~m})$. Protocols in 2007 were modified slightly; elevation was reduced to $60-90 \mathrm{~m}$ above the water when possible, and speeds were reduced to 20 knots.

\section{Results}

\section{Trammel Netting}

Trammel nets fished effectively in river backwaters and slack water found around jetties but catch rates were typically low (fewer than 1 fish per set) compared with reservoir fishing. The average catch (1999-2005) of razorback suckers per field season in the river was 43 fish. Razorback suckers represented less than 3 percent of the total fish captured during that period, and by-catch was composed mostly of common carp and a few game fish (Mueller, 2003). Not counted in those reports were small numbers of waterfowl, grebes, and muskrats. 
State game agencies received several calls from concerned citizens during the study. Several reported observing nets that contained struggling fish, and on one occasion a net contained a dead grebe. On two occasions, nets were either stolen or broke loose and were lost. Losses of game fish, other animals and birds, and a certain degree of vandalism had to be expected and accepted. The actual capture and handling of these fish allowed biologists to gather specific information for individual fish. Collected data included targeted species number, individual weight, length, and possible origin (stocking location and year).

Potential information includes the following:

- $\quad$ presence of targeted species

- information collected from individual fish

- weight (condition)

- length distribution (recruitment? [presence of small individuals])

- $\quad$ stocking origin (PIT tag marked fish)

- $\quad$ sample composition (percentage of all fish)

- relative abundance (fish numbers per square meter of netting or net set)

- $\quad$ standardized protocols could provide trend data

- mark and recapture data

- growth

- fish movements

- adult population size with wide confidence limits ( \pm 500 percent).

The technique has both strengths and weaknesses.

\section{Strengths}

1. Low tech. Trammel netting requires a boat, trammel nets, floats, weights, and other associated equipment and a minimum crew of three. Proficiency takes a minimal training.

2. Data precedent. This sampling technique has been effectively used for more than 3 decades and has produced a substantial database. Although river related data are not as prevalent as reservoir data, they nevertheless have some value for comparison purposes.

\section{Weaknesses}

1. Labor intensive. It took 10 to 12 hours to set and retrieve 12 to 14 nets. Nets are typically set in late afternoon and pulled shortly after dawn to help reduce conflicts with boaters and to minimize fish stress and associated mortalities.

2. Limited application. Trammel netting is ideally suited for deep water with little or no current. Its effectiveness diminishes as current increases; thus it is less suitable for channel sampling.

3. High by-catch. Targeted fish generally represent a small portion of the catch. The majority of fish are represented by common carp and game fish (e.g., sunfish, catfish, bass, striped bass). Waterfowl and aquatic mammals are also caught and usually killed. Diving ducks, grebes, muskrats, and beaver are quite vulnerable to entanglement and loss. Often they do considerable damage to the nets.

4. Public scrutiny: Although nets are clearly marked with buoys, netting activities are often reported by the public. Some people reported they were disturbed to find fish struggling, and they commonly believed that fish were going to die or be killed.

5. Vandalism. Nets can be accidentally destroyed by boat traffic or stolen. 
6. Sampling bias. Sampling biases include the following:

a. The nets are visible, and to a degree fish avoid nets.

b. Nets select for certain sizes; small fish and large fish can generally avoid entanglement.

c. Trammel nets are ineffective for species that avoid slack-water habitats and highly biased for those that prefer backwaters.

d. Low recapture rates minimizes the vigor of data analysis by producing high statistical variance and wide confidence intervals.

Cost

Cost estimates derived for these comparisons were based on efforts during 1999-2002. River sampling during those and subsequent years averaged six 5-day field trips.

Labor

A crew of three conducting six 5-day surveys is the equivalent of 90 staff days. For the purposes of this comparison, a staff day + travel $=\$ 500$ per day.

90 staff days @ \$500 per day $=$ $\$ 45,000$

\section{Equipment}

A vehicle, motor boat, trailer, GPS, trammel nets, and associated safety equipment (personal flotation devices (PFDs)). This equipment is common, and nets can generally be used for more than one year.

\section{Operating Costs}

Gasoline: $\$ 75$ per week x 6 weeks $=$ $\$ 450$

Operation and maintenance $($ boat $)=\ldots \ldots \ldots \ldots \ldots \ldots \ldots \ldots \ldots \$ \ldots 1,000$

Replacement of four trammel nets per year @ $\$ 300$ each...... \$1,200

Total Annual Cost.........

\section{Sampling Efficiency}

The cost of capturing razorback suckers in terms of staff days and monetary cost were calculated for trammel netting. On average 43 razorbacks sucker were captured by trammel netting per year based on an annual budget of $\$ 47,650$.

Effort: 43 captured razorback suckers divided by 90 staff days equals 0.5 razorback suckers captured per staff day.

Cost: Trammel-netting budget of $\$ 47,650$ divided by 43 captured razorback sucker equals $\$ 1,108$ per fish.

\section{Hoop Netting}

Hoop nets were set during the weeks of 30 January (8 net nights), 13 February (16 net nights), and 27 February (12 net nights), 2006. The experiment consisted of a total of 36 overnight sets; 12 contained females and the remainder set empty. Anchors frequently failed in strong currents, and nets dragged downstream until either the anchors grabbed or the nets snagged on debris (fig. 9). Dragging caused excessive wear on the fabric, especially where it was wrapped over the hoops. Nets frequently snagged and tore; requiring extensive repairs. The trap entrance may have initially been too small for larger suckers, and it was eventually enlarged from $15 \mathrm{~cm}$ to $25 \mathrm{~cm}$. Although suckers were commonly 
found around, and even in some cases observed under the traps, no razorback suckers were captured in either baited or empty traps.

Our attempts at attracting male suckers into hoop nets failed possibly owing to poorly designed or faulty equipment. We believe the entrances to the traps were too narrow to allow easy fish entry, and anchorage was inadequate. Some nets pulled loose during high flows and collapsed or were dragged downstream. As a result, we discontinued further hoop net testing and refocused our efforts on testing electrofishing in the later half of 2006 and the entire 2007 field seasons.

\section{Electrofishing}

Electrofishing was conducted during daylight hours using small-mesh dip nets better suited for smaller fish and standing water. The dip nets were difficult to use on large suckers in strong current. Regardless, 78 suckers were captured during 3 nights of shocking efforts during the end of January and early February, 2006. Electrofishing was attempted at night because razorback suckers were found at night in the shallows along the shoreline, apparently resting, following the rigors of spawning during the day.

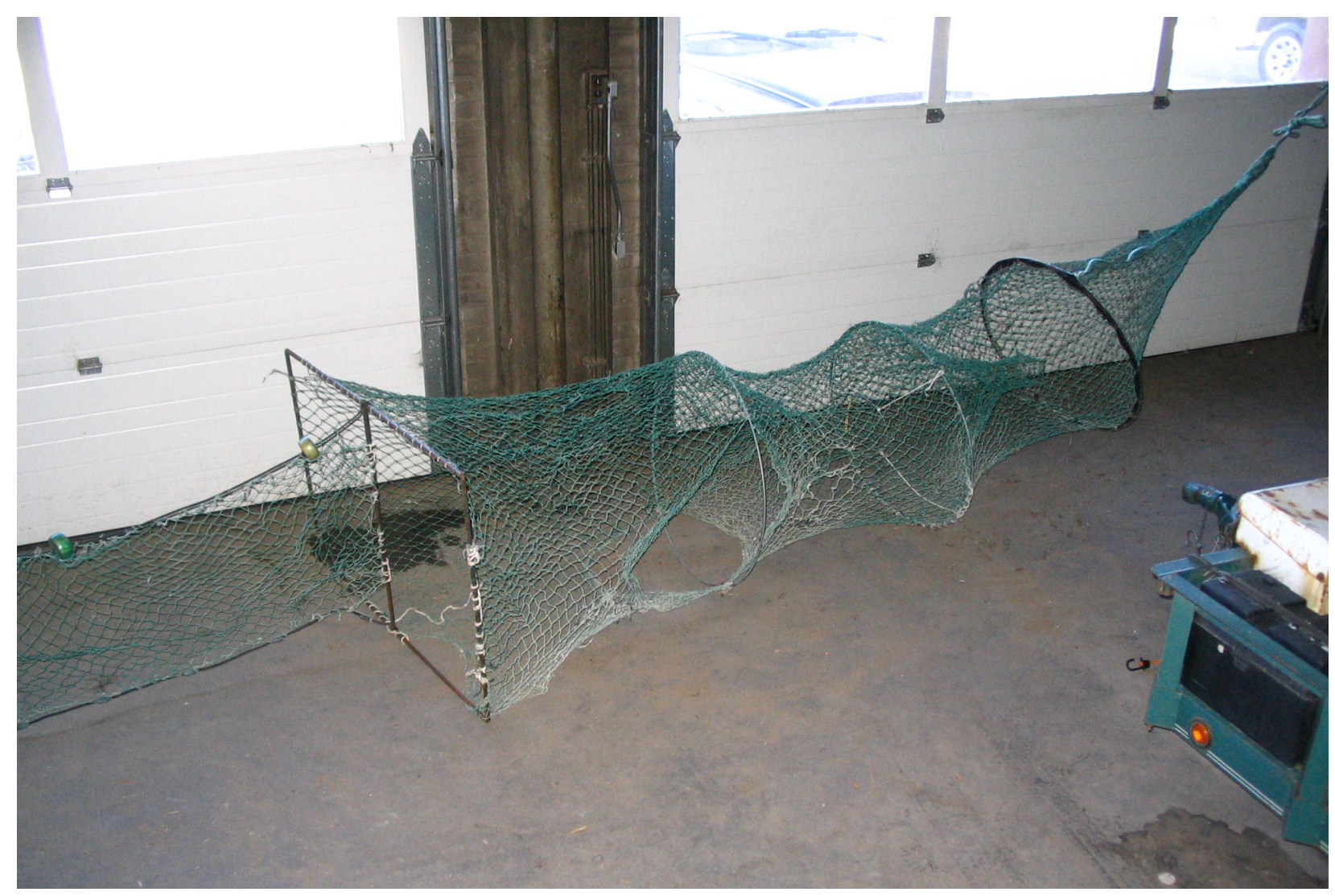

Figure 9. This hoop net was extensively damage when its anchoring system failed and it was dragged downstream by flow. A major portion of the net's bottom was worn-through from rock abrasion. 
Razorback suckers were found spawning at much shallower depths than flannelmouth suckers ( $<2 \mathrm{~m}$ versus $>3 \mathrm{~m}$ ) that spawn in the Laughlin, Nev., area. Shallow depths made them more vulnerable to capture. Rather than just capturing four for the hoop nets, dozens were easily collected along shore. To minimize our impact in 2007 , we collected no more than 100 fish per field trip. This number was easily captured in 3 nights of 3-4 hours work each.

A total of 263 razorback suckers were captured in 2006; of these only 2 had been marked the previous year using trammel nets. Based on those 2 recaptures, the 2006 population estimate was 3,341, with a 95 percent confidence range of 1,255 to 8,577 fish. This wide range was due to the small number of recaptures. In previous years, trammel netting averaged 43 fish a year in our marking efforts; with electrofishing we marked 245 razorback suckers in 2006 and another 299 in 2007. Owing to our 2006 marking effort, marked fish returns in 2007 soared to 59 fish, nearly 30 times the previous year's recapture of 2. Population estimates (and 95 percent confidence interval) for the three 2007 trips were 1,197 (805-1,860); 1,305 (898-1,973); and 1,195 (887-1,651). These estimates show increased precision compared with previous years.

To our knowledge, no mortalities of any species occurred, and only two carp were netted by mistake. We did get checked by local law enforcement authorities who were responding to a call.

Types of information collected:

- $\quad$ presence of targeted species

- individual fish data

- weight (condition)

- length distribution

- $\quad$ stocking origin

- sample (community) composition (percent)

- relative abundance (fish numbers per shocking time)

- GPS assisted information

- $\quad$ exact location of species

- habitat data (which could be collected at a later time)

- mark and recapture data

- growth

- fish movements

- adult population size (relative high recapture rates increased statistical vigor).

This technique has both strengths and weaknesses.

\section{Strengths}

1. Average training required. This approach requires an electrofishing boat and crew which are readily available to most Federal and state agencies. A shocking effort requires a minimal crew of three; one must be a boat operator knowledgeable about the navigational challenges of the river and trained in electrofishing.

2. Reliable. Only severely strong winds, lighting storms, and of course equipment failure prevent sampling. Both flowing and slack water habitats can be sampled.

3. Selectivity. Sampling can be conducted where fish are known to congregate. Nontargeted species can be ignored and not netted, preventing them from additional handling stress. Nonfish by-catch, such as waterfowl or muskrats, can be totally avoided. 
4. Security. Active sampling eliminates the problems associated with leaving passive collecting gear in the field that can be subject to vandalism, theft, or simply compromised. In remote areas, sampling can be accomplished with little or no notice by the public.

5. Captured fish. Having fish in hand allows researchers and biologists to explore more detailed research issues such as fish health, sex ratios, DNA testing, and allow for marking studies that could provide future information on population size, age, and growth information.

\section{Weaknesses}

1. Equipment cost: The cost of an electrofishing boat can easily surpass $\$ 50,000$.

2. Public scrutiny: Electrofishing has been most successful at night. However, a boat sporting high intensity lights, a noisy generator, and two people frantically netting fish arouses public suspicion. This is certainly the case in the Needles area where residential and vacation homes border the shoreline. An offsetting factor is that these activities occur at night when other boaters and other recreationists are generally off the water.

3. Effective depth. In high conductance waters, such as the lower Colorado River, the effective shocking range is limited. Suckers and other fish that generally dwell near the bottom or at depths greater than $2 \mathrm{~m}$ can avoid and escape the electrical field.

4. Impacts to fish. While electrofishing is a common and accepted method of capturing fish, there is growing concern of its long-term effect on stunned fish. Research has shown that fish subjected to electrical shock can suffer muscle, organ, and spinal injury (Snyder, 2003).

5. Sample bias

a. Samples are typically biased toward larger fish

b. Ineffective in deeper or swift flowing waters

c. Netters require a great deal of skill and proficiency that influences catch per unit effort.

d. Equipment does vary. The electrical output can vary dependent upon generator capacity, the electronics, and the type of electrode array. The length, hoop size, and mesh size of dip nets influences ease of capture.

e. Operation of the electronics and navigation (boat placement and control during sampling) influences capture rates.

Cost

The following cost estimates are based on three sampling trips of 4 days each.

Labor

A crew of 3 conducting three 3-night surveys (4 days) is the equivalent of 36 staff days. (Staff day + travel $=\$ 500)$

36 staff days @ $\$ 500$ per day = $\$ 18,000$

Equipment

A vehicle, shocking boat, trailer, GPS, polarized sunglasses, and associated safety equipment (PFDs). This equipment is common and no costs were associated with its use. 


\section{Operating Costs}

Gasoline at $\$ 75$ per trip x 3 trips $=\ldots \ldots \ldots \ldots \ldots \ldots \ldots \ldots \ldots \ldots \ldots \ldots \ldots \ldots \ldots \ldots$

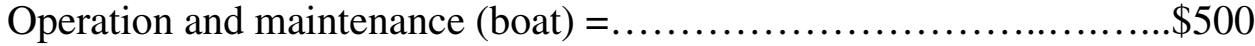

Total Annual Cost...........................................\$18,725

\section{Sampling Efficiency}

The cost of capturing razorback suckers in terms of staff days and monetary cost were calculated for electrofishing. We are using 300 razorback suckers as the average annual sample captured by electrofishing based on an annual budget of $\$ 18,725$.

Effort: 300 captured razorback suckers divided by 36 staff days equals 8.3 razorback suckers captured per staff day.

Cost: Electrofishing budget of $\$ 18,725$ divided by 300 captured razorback sucker equals $\$ 62$ per fish captured.

\section{Boat Surveys}

Surveys were conducted during the weeks of 30 January, 13 February, and 27 February of 2006 and 2007. Fifty-two 15-minute surveys were completed in 2006 and 56 in 2007 (Table 1). Water visibility was generally $3-5 \mathrm{~m}$ and water depths were typically less than $3 \mathrm{~m}$. The railed bow deck of the electrofishing boat provided a safe platform for the observer.

The effective viewing range depended upon wind, weather, and channel conditions but normally was 3-10 m, less than 10 percent of the channel's $100-\mathrm{m}$ width. Wind was a major concern because it caused surface distortions (ripples, glare) that reduced our ability to see or identify fish. Fish exhibit some degree of boat avoidance and this avoidance became an issue when conditions prevented observation at distances greater than $3 \mathrm{~m}$. Fish found at depths greater than $3 \mathrm{~m}$ and surface distortion caused by swift current also reduced ability to see fish. Daylight viewing conditions were generally best from dawn to mid-morning, before breezes developed. We continued to work until it became difficult to see fish. Wind determined our stopping time about 3 out of 4 days. Owing to the high degree of variability in daytime survey conditions, we attempted night surveys. Breezes are less prevalent after sunset and artificial light actually reduced problems associated with glare, and it provided direct light on fish and standardized lighting conditions. The additional 500-watt lights were necessary and worked well. We feel that further refinement of night surveys would help reduce variability and delays common in daylight surveys.

Table 1. Population estimates derived by surface boat counts of spawning razorbacks counted in the Colorado River near Needles, California, during 2006 and 2007. ha, hectare; min, minute; No, number; RBS, razorback sucker, Trans., transect

\begin{tabular}{ccccccc}
\hline Week & $\begin{array}{c}\text { No. } \\
\text { trans. }\end{array}$ & $\begin{array}{c}\text { Transect } \\
\text { area } \\
\text { (ha) }\end{array}$ & $\begin{array}{c}\text { No. } \\
\text { RBS }\end{array}$ & $\begin{array}{c}\text { RBS/15 min } \\
\text { (range) }\end{array}$ & $\begin{array}{c}\text { Avg. RBS/ha } \\
\text { (range) }\end{array}$ & $\begin{array}{c}\text { Population' }^{1} \\
\text { estimate }\end{array}$ \\
\hline $\mathbf{1 / 3 0 / 0 6}$ & 14 & 30.6 & 449 & $32.1(1-99)$ & $14.7(.4-51)$ & 1,764 \\
$\mathbf{2 / 1 3 / 0 6}$ & 20 & 20.6 & 304 & $15.4(0-70)$ & $14.8(0-180)$ & 1,776 \\
$\mathbf{2 / 2 7 / 0 6}$ & 18 & 10.4 & 348 & $19.3(0-85)$ & $33.5(0-125)$ & 4,020 \\
$\mathbf{1 / 3 0 / 0 7}$ & 21 & 26.9 & 391 & $18.6(0-99)$ & $14.5(0-48)$ & 1,740 \\
$\mathbf{2 / 1 2 / 0 7}$ & 21 & 29.0 & 223 & $10.6(0-21)$ & $7.7(0-22)$ & 924 \\
$\mathbf{2 / 2 7 / 0 7}$ & 14 & 9.2 & 61 & $4.4(0-22)$ & $6.6(0-28)$ & 792 \\
\hline
\end{tabular}

${ }^{1}$ Population based on study site surface area of 120 hectares $(12.1 \mathrm{~km} \times 100 \mathrm{~m})$ 
Initial surveys in 2006 were conducted heading downstream (southerly), and observers generally traveled more than $2 \mathrm{~km}$ in $15 \mathrm{~min}$. However, observers' vision was impaired by early morning glare. To reduce the glare, boat surveys switched to heading upstream, which put the sun behind them. Survey lengths decreased since we were going against the flow by more than half; however, overall fish densities increased, which suggests less boat avoidance. In 2006, we detected a bias resulting from the absence of established transect locations; boat operators tended to gravitate toward known spawning locations. Therefore, in 2007 survey protocols were subdivided into seven reaches, and monitoring was distributed evenly among the subdivisions.

Observers during the three trips counted a total of 1,101 and 675 razorback suckers in the study area in 2006 and 2007, respectively; densities for those years averaged 20.5 and 9.6 fish per ha. The lower 2007 estimate reflected a refinement in sampling approach which removed a sampling bias. Spawning population estimates were 1,764-4,020 in 2006 and 792-1,740 adult razorback suckers in 2007. In 2006, razorback sucker outnumbered other fish species 3:1 (range 2.20:1 to 3.03:1 (fig. 10)). Common carp (Cyprinus carpio) was the most prevalent "other" species, followed by rainbow trout (Salmo gairdneri), striped bass (Morone saxatilis), sunfish (Centrarchidae), and channel catfish (Ictalurus punctatus). Composition data was incomplete for 2007.

Potential information includes the following.

- verify presence of targeted species

- visually estimate community composition percentage

- potential for annual surveys to yield relative-abundance trend data (fish number per minute)

- GPS assisted

- exact location of species

- habitat data (that could be collected later)

- relative densities (fish per square hectare) of all observed fish species

- spawning population size (fish per square mile).

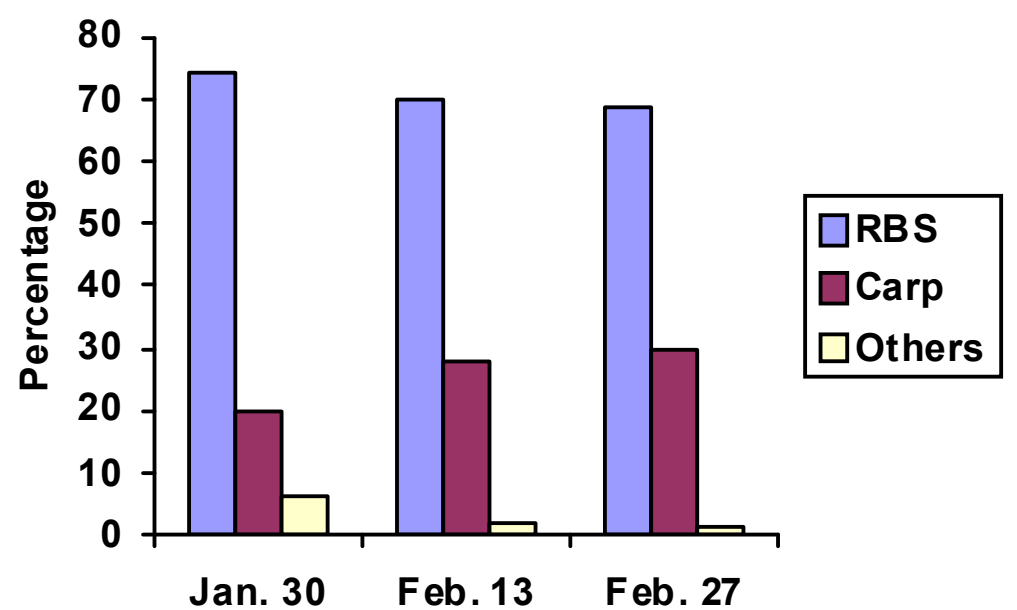

Figure 10. Species composition of fish observed during boat surveys in the Colorado River near Needles, Calif., in 2006. RBS, razorback sucker. 
The boat survey technique has both strengths and weaknesses.

\section{Strengths}

1. Low tech. This approach requires no specialized equipment, only a motor boat and a minimal crew of two (three is optimal) — one operator and one or two observers capable of visually identifying fish in the water. Advance surveys could incorporate the use of GPS to better quantify fishery data.

2. Not disruptive. Day and night boat surveys blended in with recreational boating in the area.

3. Reliable. Although wind could restrict or prevent surveys, breezes are generally less of a problem a couple of hours after dusk. Under ideal conditions, fish were visible and easily identified $10 \mathrm{~m}$ to the port and starboard sides of the boat. The application of two 500-watt halogen lights made it possible to conduct night surveys.

4. Coverage. Large areas can be covered with little cost or effort. It is most effective during spawning when razorback suckers are congregated; however, this approach could be implemented other periods of the year.

5. Nonstressful for fish. Fish are not captured nor handled.

\section{Weaknesses}

1. Weather and river conditions: Visibility is influenced by several factors. These include water turbidity and depth, surface distortion caused by current and wind, and glare caused by sun angle. All of these individually or in combination can restrict the area examined and can cause cancellations. A brief description and the likelihood of problems follow:

a. Turbidity. Turbidity typically is more of a problem during infrequent storm events. Water clarity typically exceeded $5 \mathrm{~m}$ in the mainstem river. However, increased plankton productivity distracts from water clarity in backwaters or the delta area of Lake Havasu. Razorback suckers frequent these types of habitats during nonspawning seasons to feed on abundant plankton.

b. Depth. As surface distortion increases owing to wind or currents, it becomes more difficult to detect and identify fish, especially at depths greater than $3 \mathrm{~m}$. The problem lies more in detecting single convalescing females than groups of spawning razorback suckers, which are generally found in shallower (less than $2 \mathrm{~m}$ ) water. We suspect that less than 10 percent of fish use depths greater than $3 \mathrm{~m}$ during the peak of spawning or during the night when fish appear to move toward shallower shoreline habitats.

c. Surface distortion. Spawning razorback suckers, especially active males on spawning sites, are typically found in moderate $(50 \mathrm{~cm}$ per s) flows and depths (less than $2 \mathrm{~m}$ ). These currents combined with wind distortion and glare can prevent fish from being seen. Typically, current distortion is not a problem.

d. Glare. The sun's angle (along with surface distortion) makes a significant difference on our visual range into the water and the distance we can see laterally from the boat. In a north-south stretch of river (such as the Colorado River reach at Needles), the optimal time interval was a half hour after sunrise to midmorning (10-11 am). Surveys were optimized by going upstream with the sun at our backs. Breezes generally picked up by midmorning. This interval provided 2 to 4 hours, which was sufficient to survey $12 \mathrm{~km}$ of stream. 
2. Sampling biases. Information quality can be affected by a number of factors including the following.

a. Poor training. Data generated can suffer through missed detection or identification. New observers should be paired with trained personnel who can check and confirm their performance.

b. Poor visibility. The combination of surface distortion caused by current and wind and glare from the sun reduces the depth and range at which fish can be accurately identified. There is also a threshold beyond which fish avoiding the boat can escape undetected. The minimal range where boat avoidance becomes a problem is $6-7 \mathrm{~m}$ (about $3 \mathrm{~m}$ on each side, perpendicular to the boat's center beam). Between spawning events, convalescing females probably rest in deeper pools or backwaters where visibility is poor.

c. Boat avoidance. Biologists located on vantage points along shore on several occasions observed razorback suckers that would disperse or escape to deeper waters as the boat approached. Avoidance was prevalent during the reservoir surveys but was not tested in the river.

d. Inadequate protocols. Not following agreed-upon protocols can reduce the effectiveness of monitoring efforts. Examples include heading into the sun's glare, not wearing polarized glasses, or conducting surveys under unacceptable conditions. In addition, standardized transects are needed to prevent surveyors from gravitating to known concentrations of fish, a practice that inflates counts and density estimates.

Cost

This cost comparison is based on three 1-week field trips conducting both day and night surveys during a 5-day workweek.

Labor

A crew of two conducting three 1-week surveys uses the equivalent of 30 staff days. (Staff day + travel $=\$ 500)$.

30 staff days @ \$500/d=....

$\$ 15,000$

\section{Equipment}

A vehicle, motor boat, trailer, GPS, polarized sunglasses, and associated safety equipment (for example, PFDs). This equipment is common and is not included in these costs.

Operating Costs

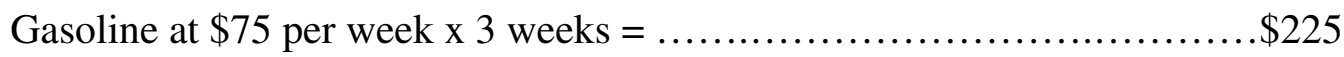

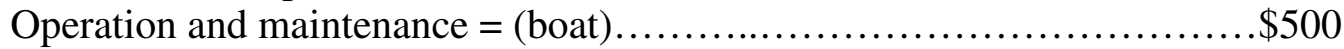

Total Annual Cost..............................................................\$15,725

\section{Sampling Efficiency}

The cost of capturing razorback suckers in terms of staff days and monetary cost were calculated for boat survey. On average, 888 razorback suckers were observed annually using boat survey techniques supported on an annual budget of $\$ 15,725$.

Effort: 888 observed razorback suckers divided by 30 staff days equals 29.6 razorback suckers observed per staff day. 
Cost: Method budget of $\$ 15,725$ divided by 888 observed razorback sucker equals $\$ 17.70$ per observation.

\section{Helicopter}

The helicopter was an excellent tool to find fish over a broad area when conditions were favorable (fig. 11). However, even with the ability to magnify fish images, seeing only their dorsal aspect made identification difficult at best (fig. 12). It was necessary to have a ground crew determine whether targeted species were present and if so in what ratio with other species. Windy conditions resulted in glare and surface distortion that made it hard to detect fish and flights were postponed both years owing to this problem (fig. 13).

Analysis of the 2006 photographs revealed the flight elevation and helicopter's speed was too great. Schools of fish were easily detected from noticing their movement in the videography; however, it was more difficult to distinguish fish from bottom debris or their shadows in the still photographs. Still photograph coverage did not overlap in either year which was a problem; however, the images could be enlarged, providing far better resolution for analysis. Fish were often detected when image resolution was enhanced that were missed in the video review. Unfortunately, the analysis process, especially when it became necessary to zoom in on still images was quite time consuming. We also detected fish avoidance problems when the aircraft dropped below $75 \mathrm{~m}$.

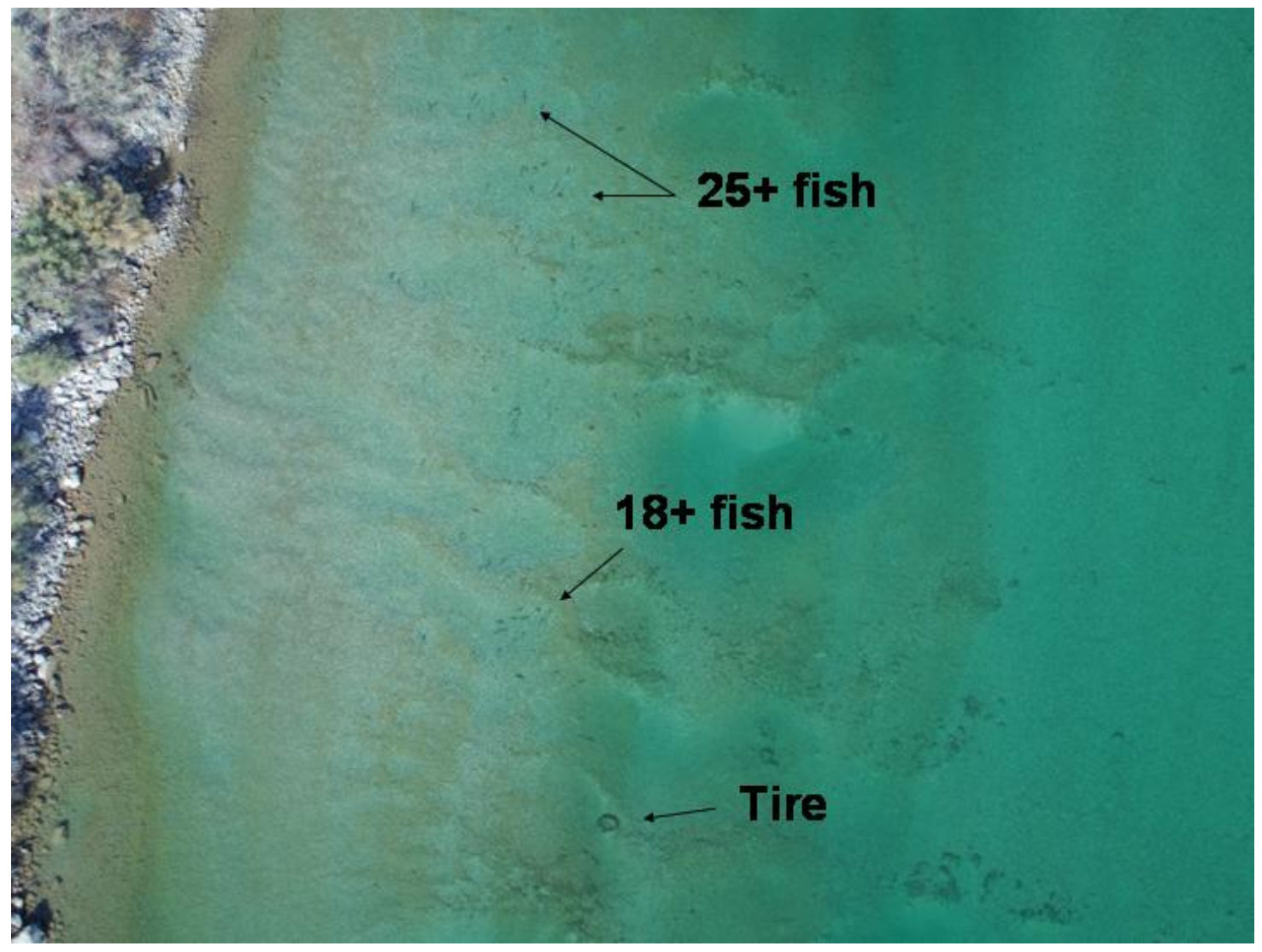

Figure 11. Aerial image of two groups of fish found in the Needles, California study area in March, 2007. Image enhancement allowed accurate counts but was not sufficient to determine if fish were razorback suckers. Field verification documented that razorback suckers were located in this area. 


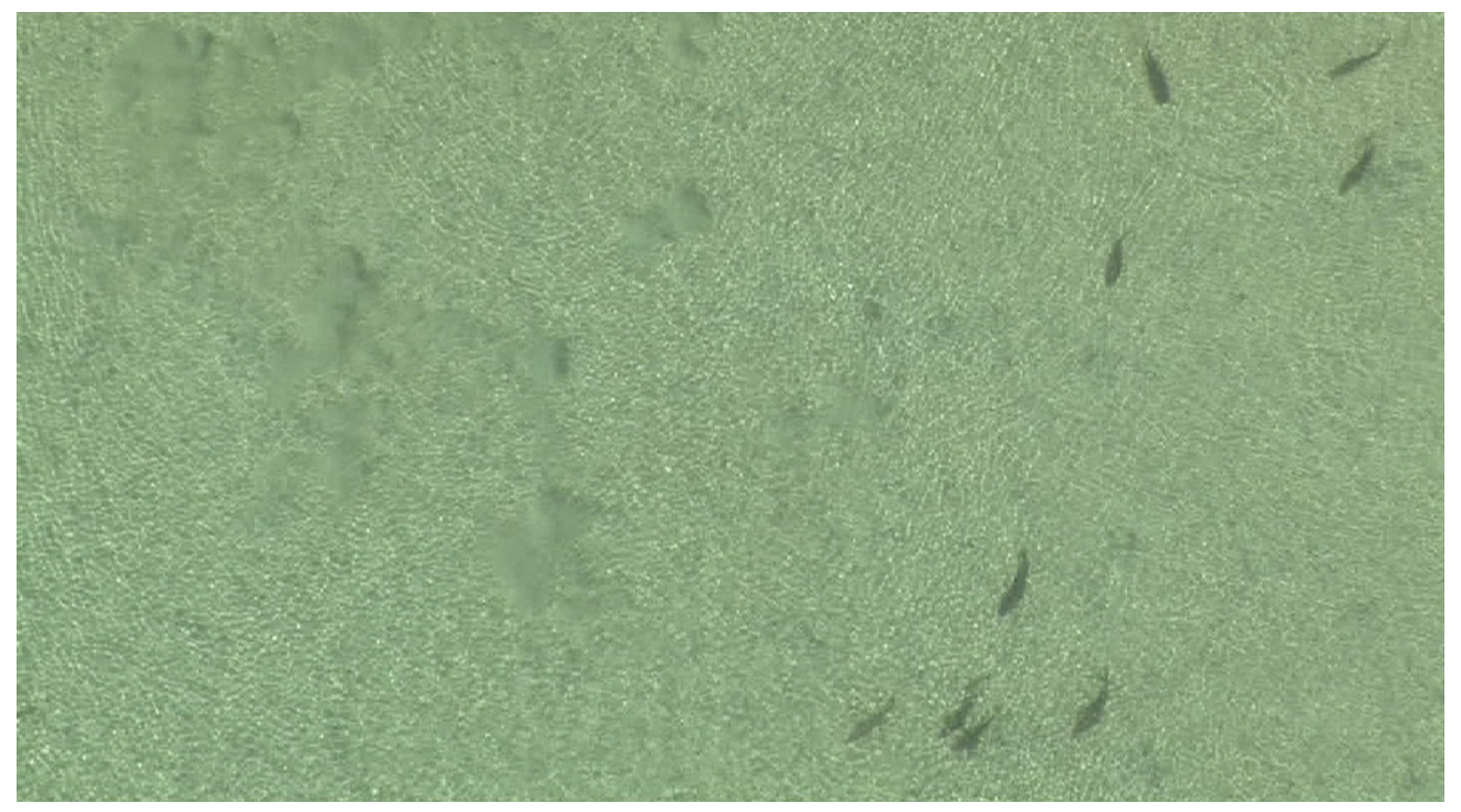

Figure 12. Enhanced imagery of suspected spawning razorback suckers in Carp Cove, Lake Mohave. Sediment clouds on the left might have been caused by spawning suckers or by feeding carp.

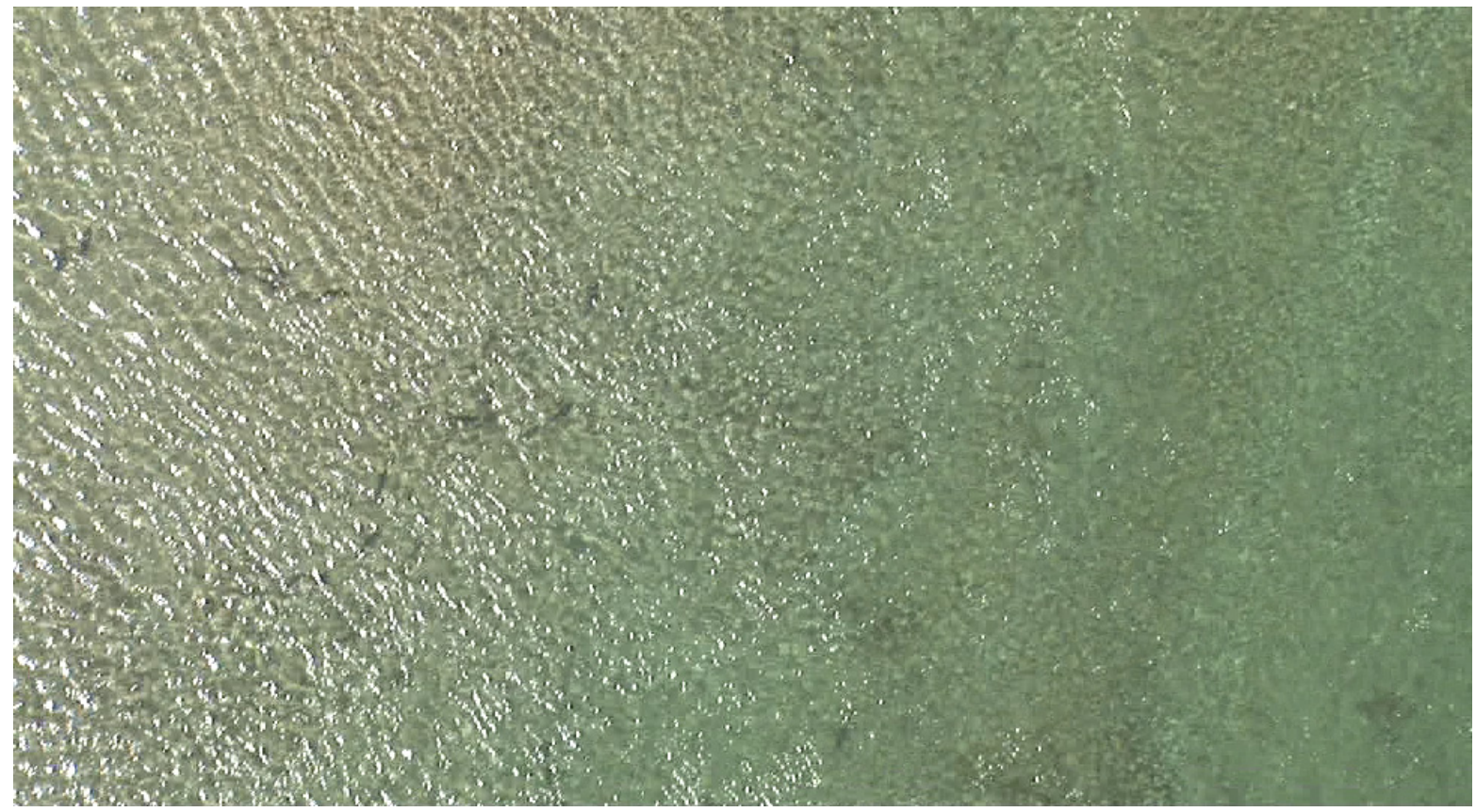

Figure 13. Surface distortion caused by natural wind or by rotor wash makes it virtually impossible to detect spawning fish. Nearly 3 dozen razorback suckers are in this photograph. 
In 2007, we attempted to fly at an elevation of $80 \mathrm{~m}$ which was possible over Lake Mohave and undeveloped portions of the river. However, the Federal Aviation Authority (FAA) restricts flying lower than $100 \mathrm{~m}$ over residential areas or power lines. The highest concentrations of fish were found in a residential area of Needles and near a power line which prevented us from flying at an optimal elevation.

\section{Image Interpretation}

Fish were detected during all flights but not at all survey areas. Fish were more numerous during the March flights for both years suggesting the later survey was nearer peak spawning activity (Table 2 and 3). Combined trip counts for each year yielded 580 fish detected for 2006 and 583 fish for 2007. This represents combined counts for both Lake Mohave and the Needles river reach. Helicopter crew visual count records were inconsistent, but when estimates were recorded, fish estimates were generally less than 50 percent lower than counts derived from photography. For instance, the flight crew in 2006 detected only 27 percent (fewer than 70) of the 260 detected on the photography (Table 2).

Results were similar for the 2007 effort; more fish were detected in the photography than from observation (Table 3). For example, in Tequila Cove of Lake Mohave, the February 2007 flight crew estimate missed 58 percent of the fish detected (60 of 144) on the imagery. More complete records were kept for the March flight where fewer than 147 (49 percent) were counted by the crew compared with 303 detected on the imagery. The imagery suggested the crew underestimated fish numbers by about half.

Table 2. Total number of fish counted by helicopter crew or detected in aerial photographs of Lake Mohave and the Needles river reach during 16 February and 22 March, 2006.

\begin{tabular}{|c|c|c|c|}
\hline \multirow{2}{*}{ Location } & \multicolumn{2}{|c|}{ Aerial Photography } & \multirow{2}{*}{$\begin{array}{c}\text { Helicopter Crew Estimates } \\
\text { March 22, } 2006\end{array}$} \\
\hline & February 16, 2006 & March 22, 2006 & \\
\hline Carp Cove & No fish detected & 165 & $20-30$ \\
\hline Yuma Cove & 164 & 83 & 30 \\
\hline Tequila Cove & No fish detected & 12 & 10 \\
\hline Needles Reach & 10 & 144 & No count taken \\
\hline Total & 176 & 404 & Fewer than 70 \\
\hline
\end{tabular}

Table 3. Comparison of fish counts taken by the helicopter crew and from aerial photography of Lake Mohave and the Needles river reach during 15 February and 1 March, 2007. Data represents the total number of fish observed or detected from the imagery.

\begin{tabular}{cccccc}
\hline & \multicolumn{2}{c}{ February 15, 2007 } & & \multicolumn{2}{c}{ March 1, 2007 } \\
\cline { 2 - 3 } \cline { 5 - 6 } Location & $\begin{array}{c}\text { Aerial } \\
\text { Photography }\end{array}$ & $\begin{array}{c}\text { Helicopter Crew } \\
\text { Estimates }\end{array}$ & & $\begin{array}{c}\text { Aerial } \\
\text { Photography }\end{array}$ & $\begin{array}{c}\text { Helicopter Crew } \\
\text { Estimates }\end{array}$ \\
\hline Carp Cove & 20 & No count taken & & 4 & 4 \\
Yuma Cove & No counts taken & No counts taken & & 68 & $35-40$ \\
Tequila & 144 & 60 & & 12 & 10 \\
Cove & 11 & No count taken & & 119 & 55 \\
9-Mile & 105 & No count taken & & 100 & 38 \\
Needles & 280 & 60 & & 303 & Fewer than 147 \\
Reach & & & & \\
Totals & & &
\end{tabular}


Initially, we had envisioned the possibility of scaling the imagery in order to measure fish densities (fish per ha) by setting and maintaining the altitude the helicopter flew to determine the surface area covered by the imagery. Owing to flight restrictions, surface distortion and glare, and the inability to identify fish we simply did not progress to that level of survey refinement.

Type of Information:

- presence of suspected targeted species,

- distribution data,

- relative abundance,

- relative densities (fish per $\mathrm{ha}^{2}$ ) of all observed fish species

- $\quad$ spawning population size

\section{Strengths}

1. Coverage. Aerial photography can cover large expanses of habitat in relatively short period time. It can also be geo-referenced and accurately compared with previous photographs to determine physical habitat changes.

\section{Weaknesses}

1. Weather and River Conditions: Wind was the greatest problem and caused us to postpone flights in both years. Unlike surface counts which could start at dawn and continue a couple of hours before the wind built, the helicopter usually would not take off until after $8 \mathrm{am}$ and by the time it reached the Needles area (about one hour) the wind usually had already built. Furthermore, the conditions for lighting in mid-day when the sun is higher in the sky made surface glare more prevalent. We believe early morning or late afternoon images would contain large shadows, making fish detection more difficult.

a. Depth. As surface distortion increased owing to wind or currents, it became more difficult to detect and identify fish at greater (greater than $3 \mathrm{~m}$ ) depths. The problem was more in the detection of a single convalescing female than groups of spawning razorback suckers which are generally found in shallower (less than $2 \mathrm{~m}$ ) water. The proportion of suckers using depths greater than $3 \mathrm{~m}$ could easily be a quarter of the population if half are female. These suckers may disperse making detection more difficult.

b. Surface distortion. Spawning razorback suckers, especially active males are typically found in moderate (50 cm per second) flows and depths (less than $2 \mathrm{~m}$ ). These currents combined with wind distortion and glare can prevent fish from being seen. Typically, surface distortion caused by wind is the primary problem in detecting fish.

c. Glare. The sun's angle (along with surface distortion) can greatly reduce our ability to detect fish. This is especially true of flights that were flown mid-day.

2. Safety issues. Spawning habitats located in the river corridor through Needles contain power line crossings, gas line crossings and bridges. It also requires flying close to levee homes. The helicopter must maintain an elevation greater than $100 \mathrm{~m}$ above homes.

3. Observational Biases. The greatest problem is the inability to distinguish fish species from their dorsal aspect in photographs. Ground truthing is necessary to determine the presence of razorback suckers and to collect species composition data which is necessary to determine abundance or estimate suckers numbers. 
4. Bottom Contrast. On calm days, fish are readily detected in Lake Mohave primarily owing to the contrast of dark fish against light substrate. Coloration in the river is more complex owing to debris, snags, dark rock and aquatic vegetation which make fish detection more difficult, especially for individuals or small schools.

\section{Cost}

The cost associated with collection, ground truthing, analysis and use of the equipment is high and requires a high degree of technical expertise. Data collection requires the use of a helicopter, pilot, biologist and camera operator and prep time to mount equipment and get necessary FAA clearances. A boat crew is necessary to ground truth suspected sightings and determine the ratio of target species to others. Once imagery is collected, video analysis must be conducted. Once suspected groups of fish are detected on the video recording, the associated still frame photographs are observed and enhanced as necessary to make accurate counts. For every hour of flight video, analysis could easily take several days.

Labor

Prep and helicopter flight $(1 \mathrm{~d}) .6$ staff days per trip. Reconnaissance and ground truthing. 10 staff days per trip times 3 trips $=48$ staff days plus 10 days for photo analysis.

52 days @ \$500 per day $=$ $\$ 26,000$

Equipment

Helicopter time $(\$ 800$ per hour $\times 3$ hour $\times 2$ trips $)=$ $\$ 4,800$

Camera purchase or rental (borrowed) Video editing equipment

(already available)

Total Cost. $\$ 30,800$

\section{Sampling Efficiency}

Estimates represent the effort (staff days) and cost to observe a razorback sucker based on the 2006 and 2007 effort. Speciation could not be determined from the photography making it necessary to estimate the number of razorback suckers from the total number of fish observed. We used composition ratios (3:1) developed during the boat surveys to determine cost estimates. Cost and staffing needed to support a surface survey were included in the cost estimates. Based on the 580 fish observed using this technique, we estimate 435 were razorback suckers based on the species composition ratio of 3:1 ratio. Associated effort and costs are:

Effort: 435 estimated razorback suckers divided by 52 staff days equals 8.4 razorback suckers observed per staff day.

Cost: Method budget of $\$ 30,800$ divided by 435 estimated razorback suckers equals $\$ 77.70$ per observation.

\section{Comparative Analysis}

In terms of methods that captured or detected razorback suckers, boat surveys were the most effective, followed by electrofishing, helicopter surveys and then trammel netting (Table 4). Although hoop nets were initially tested, the nets proved ineffective in the river environment and further testing was suspended. In terms of indirect methods, boat surveys detected 29.6 razorback suckers per staff day, 
Table 4. Total cost, cost per razorback sucker, and the number of staff days per razorback sucker caught for trammel netting or electrofishing and observed by boat surveys and on aerial photographs used in the Davis to Parker Dams reach of the Colorado River, Nevada-California, and Arizona.

\begin{tabular}{cccccc}
\hline Method & Direct/Indirect & \# RBS & Cost & Cost per RBS & RBS/Staff Day \\
\hline Trammel & Direct & $43 / \mathrm{yr}$ & $\$ 47,650$ & $\$ 1,108$ & 0.5 \\
Electrofishing & Direct & $300 / \mathrm{yr}$ & $\$ 18,725$ & $\$ 62$ & 8.3 \\
Boat survey & Indirect & $888 / \mathrm{yr}$ & $\$ 15,725$ & $\$ 18$ & 29.6 \\
Helicopter & Indirect & $435 / \mathrm{yr}$ & $\$ 30,800$ & $\$ 78$ & 8.4 \\
\hline
\end{tabular}

at a cost of approximately $\$ 18$ per fish. Helicopter surveys detected 8.4 RBS/SD at an approximate cost of $\$ 78$ per fish. For direct methods, electrofishing proved the most effective method to actually collect fish; yielding 8.3 razorback suckers per staff day at a cost of approximately $\$ 62$ per fish. In contrast, trammel netting yielded 0.5 razorback sucker per staff day at a cost of $\$ 1,108$ per fish. All new methods surpassed trammel netting in staff efficiency.

Monitoring techniques were ranked using an analysis matrix which rated impacts to the resource, cost, and ease of implementation, types of data and data accuracy as ranking criteria (Table 5). Numerical scores were given in terms of how a specific factor compared with trammel netting which scored neutral $(0)$. If the new technique was better it scored positive $(+1$ to +3$)$, if it was worse, it scored negative $(-1$ to -3$)$ and if it was similar it was scored 0 . The average value of each of the five criteria was averaged to provide a total score. Aerial photography scored similar $(-0.5)$ and both boat surveys $(+2.2)$ and electrofishing scored $(+1.8)$ far better than trammel netting.

Aerial photography had less negative impacts to the resource than trammel netting and was less (25 percent) costly; however, it scored lower in the other parameters. While fish could be found effectively without impacting other organisms, it was subject to delays from windy conditions, and the presence of targeted species could only be substantiated by ground surveys. There were also safety issues pertaining to flight restrictions over residential areas and power lines which made it necessary to deviate from desired flight elevations. Changes in flight elevation made it impractical to use the imagery for population estimates. We did receive complaints from residents in the area of helicopter noise.

Overall boat surveys scored the highest. Impacts to the resource were significantly less for boat surveys than any other method tested. Targeted fish were identified without handling, there was no incidental catch and the technique blends in with other boat traffic in the area. It required roughly one third the funding $(\$ 15,725$ versus $\$ 47,650)$ and could be implemented more easily than trammel netting. This indirect method also provided other types of information. Spawning effort could be estimated based on fish density/area and habitat and spawning locations could be documented. It also resulted in more data pertaining to the fish community at spawning locations. While trammel netting was effective in capturing fish in nonspawning areas, targeted species made up an extremely small $(<1$ percent) proportion of the sample. If monitoring the target species is the sole objective, handling these other fish is unnecessary.

Electrofishing ranked second, following boat surveys in terms of total score. It had minimal or no impact to other resources and allowed biologists to locate, handle, or observe hundreds of fish. While incidental take was insignificant, it scored similar to trammel netting for possible impacts to targeted species and we experienced complaints from the public. It required substantially less (less than 30 percent) funding, and required a crew similar to trammel netting, but required half the time and effort. It ranked highest in terms of the type and accuracy of data collected. Fish were readily available to capture. It provides a far better method of monitoring razorback suckers if used in moderation (Table 5). 
Table 5. Ranking of trammel netting, aerial photography, boat survey, and electrofishing in terms of their effect on the resource, cost, and ease of implementation, types of data, and accuracy of resulting data.

\begin{tabular}{|c|c|c|c|c|}
\hline Comparative Factors & $\begin{array}{c}\text { Trammel } \\
\text { Netting }\end{array}$ & $\begin{array}{c}\text { Aerial } \\
\text { Photography }\end{array}$ & Boat survey & Electrofishing \\
\hline \multicolumn{5}{|l|}{ Impact to resource } \\
\hline Targeted Fish & 0 & +3 & +3 & 0 \\
\hline Other animals & 0 & +2 & +3 & +3 \\
\hline Human conflict & 0 & 0 & +3 & 0 \\
\hline \multicolumn{5}{|l|}{ Cost } \\
\hline Labor & 0 & +2 & +2 & +1 \\
\hline Analysis & 0 & -2 & +1 & +1 \\
\hline Implementation & 0 & -3 & +2 & +2 \\
\hline Reliable & yes & no & yes & yes \\
\hline Training needs & no & yes & yes & yes \\
\hline \multirow{9}{*}{$\begin{array}{l}\text { Types of Data } \\
\text { Presence } \\
\text { Habitat use } \\
\text { Growth } \\
\text { Movement } \\
\text { Abundance } \\
\text { Population } \\
\text { Spawning sites } \\
\text { Spawning effort }\end{array}$} & 0 & -2 & +2 & +3 \\
\hline & yes & no & yes & yes \\
\hline & no & no & yes & yes \\
\hline & yes & no & no & yes \\
\hline & yes & no & no & yes \\
\hline & yes & no & yes & yes \\
\hline & no & no & no & yes \\
\hline & no & yes & yes & yes \\
\hline & no & no & yes & yes \\
\hline \multicolumn{5}{|l|}{ Data } \\
\hline Coveraqe & 0 & +3 & +3 & +1 \\
\hline Accuracy & 0 & -1 & +2 & +3 \\
\hline Comparison average & 0 & -0.5 Similar & +2.2 Far better & +1.8 Far better \\
\hline
\end{tabular}

Rankings: $<2.5=\mathrm{Bad},-2.5$ to $-1.6=$ Far worse, -1.5 to $-0.6=$ Poorer, -0.5 to $+0.5=$ Similar to trammel netting, 0.6 to $1.5=$ Better, 1.6 to $2.5=$ Far better, $>2.5=$ Excellent

An argument can be made that trammel netting prior to the discovery of the Needles spawning group is not representative of a similar effort had the spawning site been known. This is true; however, to effectively use trammel nets they would have to be set in marinas or off private dock and jetty structures. These locations pose safety hazards to humans and recreational boating which was not tolerated in the previous work. We concede that capture rates might be increased if trammel nets were used in the immediate area; however, that approach is deemed unrealistic owing to public safety issues, and there would still be the issue of sample bias toward females.

The last issue deals with our failure with the hoop nets. Problems dealing with poor anchorage and the small diameter of the hoop nets entrances prevented an adequate test of the concept that female pheromones would attract and capture male suckers. We feel this approach still has potential and encourage others to test this concept.

\section{Examples of Data.}

The purpose of this study was to test and refine monitoring techniques; not monitor the population. However, during technique development information was collected, and examples are presented below. This presentation is made to illustrate the types of information that can be collected from boat surveys or electrofishing or a combination of both. We urge caution, however, actual data 
may not be comparable from one year to another because of changes in technique, effort, and areas surveyed. Once a protocol is developed, implemented and followed, annual trend data should be valid.

The first example is a distribution map that was generated using ArcInfo based on GPS coordinates taken during boat surveys and electrofishing of razorback suckers during 2007 (fig. 14). This data is most easily collected during boat surveys, but it can also be collected by a fourth crew member during electrofishing. We tried with a three person crew, but operating the boat and dip netting simply did not leave sufficient time to record GPS data.

Georeferencing fish location provides a strong visual representation of the distribution and concentration of spawning razorback suckers through the spawning reach. Documenting the location and use of areas can be used to refine transects placement, or simply to determine if there are annual shifts in use or areas used. It might also be used to determine the impact of further development or some other factor that might cause these fish to move.

\section{Boat Surveys 2006-2007}

The presence of razorback suckers is easily confirmed and quantified in terms of fish observed per unit time for relative abundance information or used to develop population estimates based on fish per area if distance information is taken (Table 6). Population size can then be estimated using density data and the known area of river being used. The decline in 2007 estimates reflects an attempt to standardize transect locations and efforts. We feel the 2006 estimates were inflated, being biased by repeated surveys in locations where fish had been encountered before. It is important to develop a random transect design and maintain field discipline to sample only those locations. In 2006, we did not have a transect design.

Table 6. Comparison of data collected for 2006 and 2007 using visual boat survey techniques.

\begin{tabular}{lcc}
\hline & $\mathbf{2 0 0 6}$ & $\mathbf{2 0 0 7}$ \\
\hline Presence & Yes & Yes \\
Fieldtrips (days duration) & $3(8)$ & $3(9)$ \\
Average number razorback sucker per day & 138 & 74 \\
Total razorbacks Seen & 1,101 & 675 \\
Spawner density average (fish per ha) & $20.5(14.7-33.5)$ & $9.6(6.6-14.5)$ \\
Spawning population range & 1,764 to 4,020 & 792 to 1,740 \\
\hline
\end{tabular}

\section{Electrofishing Data}

Razorback suckers were easily captured by electrofishing with minimal effort (Table 7). The technique can provide relative abundance in terms of fish captured per unit time of shocking. Actually capturing fish allows for mark recapture techniques which can be used to develop accurate population size information as well as obtaining other population demographics. The wide confidence limits $(1,255$ to 8,577 ) for the 2006 estimates were based on a limited number (fewer than 50) of razorback suckers marked the previous year through trammel netting and recaptured $(n=2)$ in 2006. Accuracy greatly increased in 2007 with the marking of 245 razorback suckers from the 2006 electrofishing effort. This method's accuracy far surpasses previous attempts at monitoring population size for the species anywhere else in the basin (Table 7). 


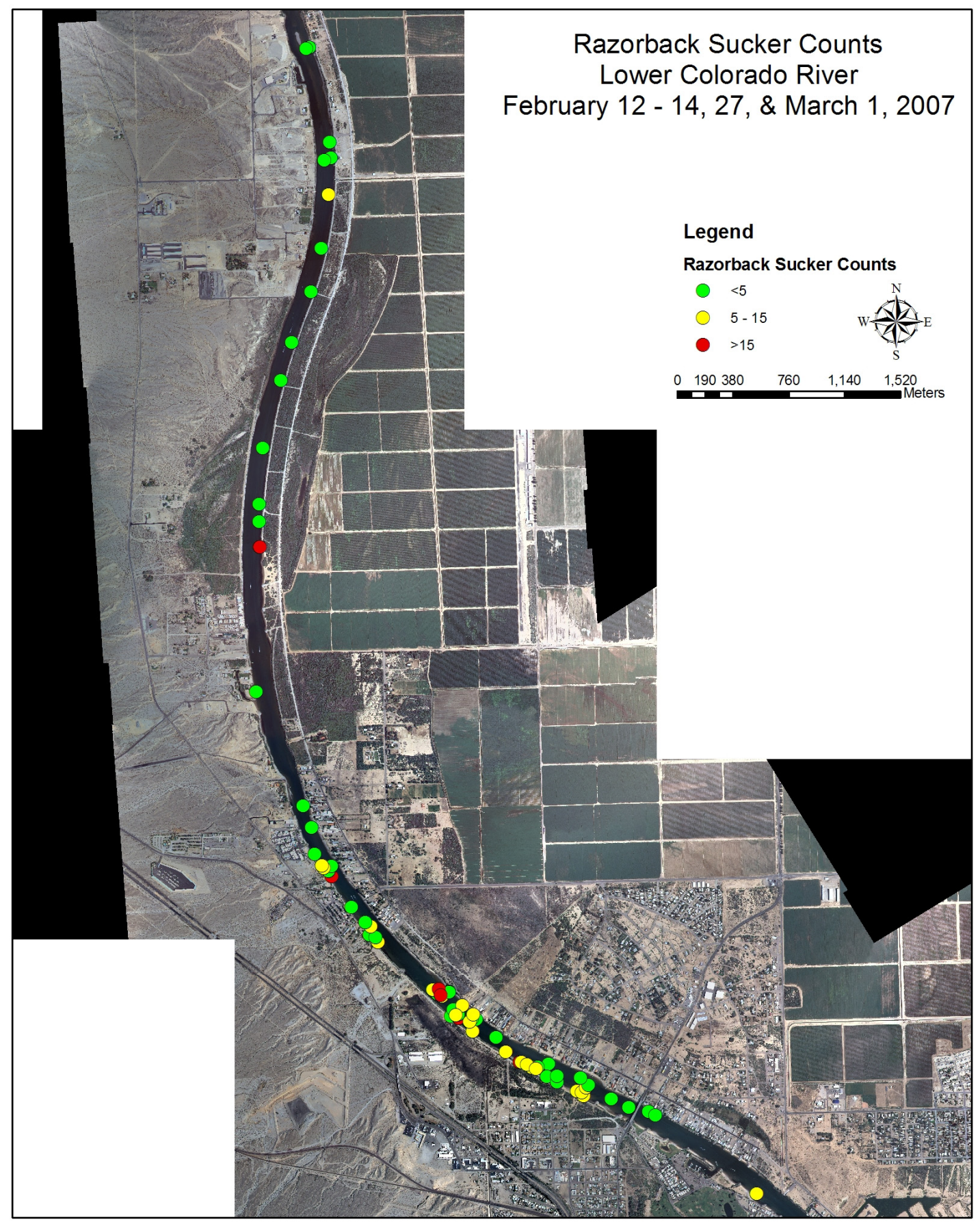

Figure 14. Distribution of razorback sucker in the Colorado River near Needles, Calif.; distribution based on boat survey data. 
Table 7. Comparison of data collected for 2006 and 2007 using electrofishing techniques. RBS/SD, razorback sucker per staff day.

\begin{tabular}{lcc}
\hline & $\mathbf{2 0 0 6}$ & $\mathbf{2 0 0 7}$ \\
\hline Presence & Yes & Yes \\
Field trips (days) & $3(8 \mathrm{~d})$ & $3(9 \mathrm{~d})$ \\
Average RBS/SD & 11.0 & 11.1 \\
Total razorbacks Captured & $263^{1}$ & 299 \\
Previous Recaptures & $2^{2}$ & 59 \\
Total Population & 3,431 & 1,196 \\
(95\% CL range) & $(1,255-8,577)$ & $(925-1,546)$ \\
\hline
\end{tabular}

${ }^{1}=245$ fish marked (18 repeat captures)

${ }^{2}=$ Marked fish based on 2005 trammel netting capture

\section{Discussion}

Hoop netting was dropped from further evaluation (2006) owing to equipment design failure and with the discovery of how effective electrofishing was. Electrofishing, boat surveys, and aerial photography survey methodologies were further evaluated in both 2006 and 2007. The results of those tests confirmed inherent problems with aerial photography which involved flight delays owing to windy conditions, problems with fish identification, and safety restrictions of flying over power lines and residential areas. While it provides an excellent method for finding fish, it is less reliable and more costly than electrofishing or boat surveys.

Electrofishing and boat surveys proved to be not only more cost effective (fig. 15) but also were more accurate and caused less impact to the resource compared with trammel netting. Collecting razorback sucker using trammel netting was $20+$ times more costly than electrofishing. Boat surveys provided more accurate information without the need to handle fish at greater than 1/50 of the cost. These two techniques should be further refined to mitigate biases or problems we encountered during the past two years. The following discussion provides suggestions to improve both of these survey techniques for razorback suckers.

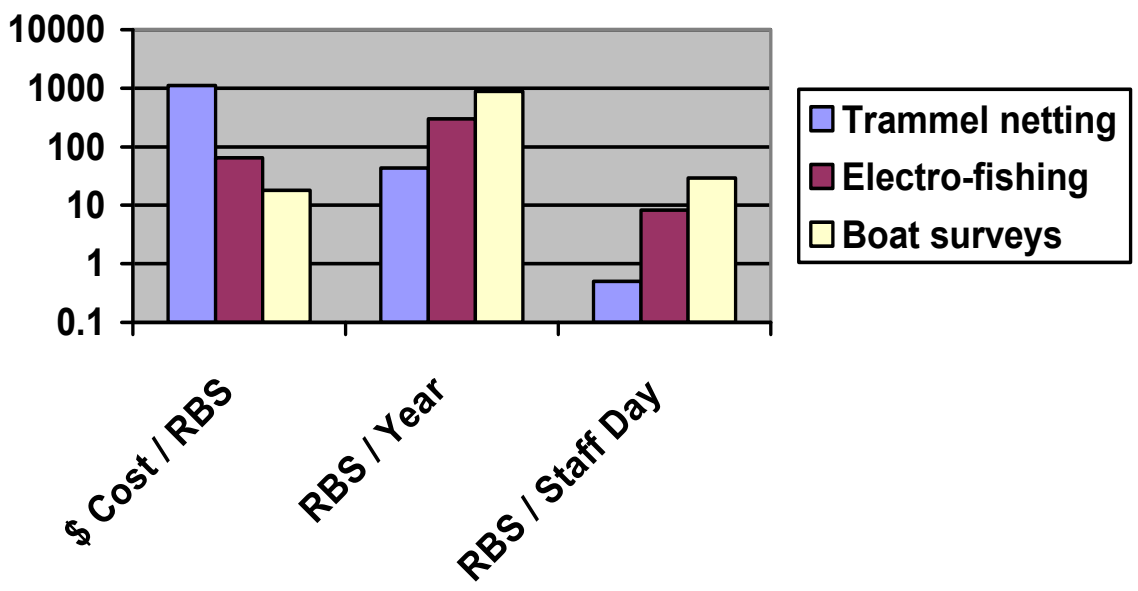

Figure 15. Comparison of the number of razorback suckers (RBS) captured per year, the dollar cost of detecting one fish (capture or identification), and the number of razorback suckers detected per staff day of effort for trammel netting, electrofishing, and boat survey. (Scale is logarithmic.) 


\section{Electrofishing}

We suggest future surveys consider limiting collections to not more than one hundred fish per field trip (week) and limit effort to 3 field trips per spawning season in order to minimize potential impacts to the population. Razorback suckers are often encountered in groups which results in a relatively large number of individuals being stunned at the same time. We endeavor to remove fish as rapidly as possible from the electric field which is difficult at times. Stunned fish often are observed rolling unconscious along the river's bottom and at depths too difficult to net. Strong river currents combined by the distance and resistance of the net in the water makes their retrieval difficult. Longer (4 $\mathrm{m}$ ) handled nets that have larger hoops and mesh bags would reduce water resistance and make the nets more maneuverable in the water.

In 2007, our attempt at subdividing the study area into 7 reaches was not effective because zone boundaries proved difficult to distinguish after nightfall. Future work should consider reducing their number and determine ways (lighting, GPS, etc) to make these more distinguishable in the dark.

\section{Boat Surveys}

The bias we perceived in the 2006 data set possibly revealed itself in a 39 percent reduction (1,101 to 675) we experienced in the 2007 estimate (Table 6). During 2006, it became apparent that boat surveys gravitated toward river locations where concentrations of spawning razorback suckers had been observed before. This would artificially inflate density estimates and can help explain the decline seen in 2007. In 2007, this problem was partially rectified by splitting the spawning reach into 7 zones which purposely distributed surveys over the entire spawning reach. This was practical for daylight surveys but proved a problem at night when it was more difficult to determine location. This also plagued electrofishing but the bias is less significant in mark recapture estimates. The problem could be remedied by reducing the number of zones and selecting boundaries that are more noticeable at night. Another option will be to set out net or shore lights on designated boundaries and remove them when the work is finished that night.

Another problem was related to equipment. The additional light array had to be powered with a separate generator whose exhaust frequently became a problem for the boat operator. Neither of the shocking boats had a 120 volt alternating current outlet that could be used to power the lights; having an outlet installed would eliminate the need to use another generator.

It appears there was a good deal of boat avoidance by razorback suckers in Lake Mohave. Conversely, this only appears to be a problem in the river surveys when surface distortion limits observations to less than $5 \mathrm{~m}$. In the river, fish seemed reluctant to leave their riverine positions or possibly they were more conditioned to boats. Reclamation biologists suggest surveys taken from high vantage points along shore may be another approach.

\section{Acknowledgments}

Aspects of this study were funded or supported by the Multi Species Conservation Program, California Department of Fish and Game (Blythe Office), Arizona Fish and Game Department, Bureau of Reclamation and U.S. Geological Survey. Monitoring was conducted under scientific permits issued by USFWS, CDFG and AFGD. Electrofishing boats were provided by CDFG and USBR and operated by Captains Joe Millosovich, Jeff Lantow and Gordon Mueller. GIS data interpretation and map was developed by Vicki Johanson. We thank the many other volunteers who participated. 


\section{References Cited}

Best, E., and Lantow, J., 2007, Investigations of flannelmouth sucker habitat use, preference and recruitment downstream of Davis Dam, in the Lower Colorado River, Bureau of Reclamation, Technical Services Center, Fisheries and Wildlife Resources Group, Denver, Colorado, 37 p.

Catalano, M. D. Therry, R. Quihillalt, and Shaw, T.A., 1997, Mainstem Klamath River fall chinook spawning redd survey, U.S. Fish and Wildlife Service, Coastal California Fish and Wildlife Office, Arcata, California, 27 p.

Douglas, P.A., 1952, Notes on the spawning of the humpback sucker Xyrauchen texanus (Abbott): California Fish and Game, v. 38, no. 2, p. 148-155.

Killam, D., and Harvey-Arrison, C.H., 2003, Chinook salmon spawner populations for the Upper Sacramento River Basin, 2003, Sacramento River Salmon and Steelhead Assessment Project, Technical Report No. 04-3, California Department of Fish and Game, Sacramento, 30 p.

Marsh, P.C., Kesner, B.R., and Pacey, C.A., 2005, Repatriation as a management strategy to conserve a critically imperiled fish species, North American Journal of Fishery Management, v. 25, p. 547-556.

Minckley, W.L., 1983, Status of the razorback sucker, Xyrauchen texanus (Abbott), in the lower Colorado River basin. The Southwestern Naturalist, v. 28, p. 165-187.

Minckley, W.L., Marsh, P.C., Brooks, J.E., Johnson, J.E., and Jensen, B.L., 1991, Management toward recovery of the razorback sucker, in Minckley, W.L., and Deacon, J.E., eds., Battle Against Extinction: University of Arizona Press, Tucson and London. Chapter 17, p. 303-356.

Mueller, G.A., 2003, The role of stocking in the reestablishment and augmentation of native fish in the lower Colorado River mainsteam (1998-2002), Open-File Report 03-288, U.S. Geological Survey, Denver, Colorado.

Quang, P.X., and Lanctot, R.B, 1991, A line transect model for aerial surveys, Biometrics, v. 47, p. 1089-1102.

Skinner, R.,W., Erickson, L., McDonald, and Minick, G., 1997, Estimating moose populations and trends using line transect sampling, U.S. Fish and Wildlife Service, McGrath, Alaska and WEST Inc. Cheyenne, WY. 53 p.

Snyder, D.E., 2003, Electrofishing and its harmful effects on fish, Information and Technology Report, USGS/BRD/ITR—2003-0002, U.S. Government Printing Office, 149, p.

Wydoski, Richard., and Mueller, G.A., 2006, The status of razorback suckers in the Colorado River between Davis and Parker Dams (Lake Havasu), 2003 to 2005, Technical Memorandum No. 8668220-06-19, Bureau of Reclamation, Denver, Colorado.

West, I.F., and Godde, R.H., 1987, Aerial counts of spawning Chinook salmon (Oncorhynchus tshawytscha) on the Rakaia River system, Canterbury, New Zealand, 1973-76, New Zealand Journal of Marine and Freshwater Research, v. 21, p. 563-572.

Publishing support provided by:

Denver Publishing Service Center

For more information concerning this publication, contact: Center Director, USGS Fort Collins Science Center 2150 Centre Ave., Bldg. C

Fort Collins, CO 80526-8118

(970)226-9398

Or visit the Fort Collins Science Center Web site at: http://www.fort.usgs.gov/ 